PART I: STI PRODUCT DESCRIPTION

(To be completed by Recipient/Contractor

\section{A. STI Product Identifiers}

1. REPORT/PRODUCT NUMBER(s)

None

2. DOE AWARD/CONTRACT NUMBER(s)

DE-FC36-99GO10449

3. OTHER IDENTIFYING NUMBER(s)

\section{B. Recipient/Contractor}

University of Central Florida

C. STI Product Title: Solar Photocatalytic Hydrogen Production from Water Using a Dual Bed Photosystem

\section{Author(s)}

Linkous, C.L. ; Slattery, D.K. ; Fowler, J.R.

\section{E-mail Address(es):}

calink@fsec.ucf.edu

dkslatt@fsec.ucf.edu

rfowler@fsec.ucf.edu

\section{E. STI Product Issue Date/Date of Publication} 02/28/2003 (mm/dd/yyyy)

F. STI Product Type (Select only one)

$X \quad$ 1. TECHNICAL REPORT

$X$ Final $\square$ Other (specify)

2. CONFERENCE PAPER/PROCEEDINGS

Conference Information (title, location, dates)

3. JOURNAL ARTICLE
a. TYPE: $\square$ Announcement Citation Only $\square$ Preprint $\square$ Postprint
b. JOURNAL NAME
c. VOLUME
d. ISSUE
e. SERIAL IDENTIFIER (e.g. ISSN or CODEN)

OTHER, SPECIFY

G. STI Product Reporting Period ( $\mathrm{mm} / \mathrm{dd} / \mathrm{yyyy})$

$10 / 01 / 2000$

Thru 06/30/2002
H. Sponsoring DOE Program Office

Hydrogen Program, EERE

I. Subject Categories (list primary one first)

Keywords: Hydrogen; photocatalysis

\section{J. Description/Abstract}

K. Intellectual Property/Distribution Limitations

(must select at least one; if uncertain contact your Contracting Officer (CO))

X1. UNLIMITED ANNOUNCEMENT (available to U.S. and non-U.S. public; the Government assumes no liability for disclosure of such data)

2. COPYRIGHTED MATERIAL: Are there any restrictions based on copyright? $\square$ Yes $\square$ No If yes, list the restrictions as retained in your contract

3. PATENTABLE MATERIAL: THERE IS PATENTABLE MATERIAL IN THE DOCUMENT INVENTION DISLOSURE SUBMITTED TO DOE: DOE Docket Number: S-

(Sections are marked as restricted distribution pursuant to 35 USC 205)

4. PROTECTED DATA: $\square$ CRADA $\square$ Other If other, specify Release date ( $\mathrm{mm} / \mathrm{dd} / \mathrm{yyyy})$

5. SMALL BUSINESS INNOVATION RESEARCH (SBIR) DATA

Release date (Required,

(No more than 4 years from date listed in part 1.E above)

6. SMALL BUSINESS TRANSFER (STTR) DATA

Release date (Required,

No more than 4 years from date listed in part 1.E above)

7. OFFICE OF NUCLEAR ENERGY APPLIED TECHNOLOGY

L. Recipient/Contractor Point of Contact Contact

for additional information (contact or organization name to be included in published citations and who would receive any external questions about the content of the STI Product or the research contained therein)

Clovis A. Linkous, Senior Research Scientist

Name and/or Position

calink@fsec.ucf.edu

(321) 638-1447

E-mail Phone

UCF-Florida Solar Energy Center Organization 
PART II: STI PRODUCT MEDIA/FORMAT and

\section{LOCATION/TRANSMISSION}

(To be completed by Recipient/Contractor)

\section{A. Media/Format Information:}

1. MEDIUM OF STI PRODUCT IS:

$\square$ Electronic Document $\square$ Computer medium

$\square$ Audiovisual material $\times$ Paper $\square$ No full-text

2. SIZE OF STI PRODUCT 50 pages; 9 figures

3. SPECIFY FILE FORMAT OF ELECTRONIC DOCUMENT BEING TRANSMITTED, INDICATE:

$\square$ SGML $\square$ HTML $\square$ XML $\square$ PDF Normal $\square$ PDF Image

$\square$ WP-Indicate Version (5.0 or greater)

Platform/operating system

X MS-Indicate Version (5.0 or greater)

Platform/operating system Windows 95

$\square$ Postscript

4. IF COMPUTER MEDIUM OR AUDIOVISUAL

a. Quantity/type (specify)

b. Machine compatibility (specify)

c. Other information about product format a user needs to know:

B. Transmission Information:

STI PRODUCT IS BEING TRANSMITTED:

$\square$ 1. Electronic via Elink

$X$ 2. Via mail or shipment to address indicated in award document (Paper products, CD-ROM, diskettes, videocassettes, et.)

2a. Information product file name (of transmitted electronic format)
PART III: STI PRODUCT REVIEWIRELEASE INFORMATION

(To be completed by DOE)

\section{A. STI Product Reporting Requirement Review:}

$\square$ 1. THIS DELIVERABLE COMPLETES ALL REQUIRED DELIVERABLES FOR THIS AWARD

2. THIS DELIVERABLE FULFILLS A TECHNICAL REPORTING REQUIREMENT, BUT SHOULD NOT BE DISSEMINATED BEYOND DOE.

\section{B. DOE Releasing Official}

$\square$ 1. I VERIFY THAT ALL NECESSARY REVIEWS HAVE BEEN COMPLETED AS DESCRIBED IN DOE G 241.1-1A, PART II, SECTION 3.0 AND THAT THE STI PRODUCT SHOULD BE RELEASED IN ACCORDANCE WITH THE INTELLECTUAL PROPERTY/DISTRIBUTION LIMITATION ABOVE.

Released by (name)

Date (mm/dd/yyyy)

E-mail

Phone 


\title{
SOLAR PHOTOCATALYTIC HYDROGEN PRODUCTION FROM WATER USING A DUAL BED PHOTOSYSTEM
}

\author{
Phase II Final Report \\ 2000-2002 \\ Clovis A. Linkous \\ Darlene K. Slattery \\ J. Randy Fowler
}

Clovis A. Linkous, Sr. Research Scientist

Florida Solar Energy Center

University of Central Florida

Cocoa, FL 32922-5703

$\mathrm{Ph}$ (321) 638-1447

Fax (321) 638-1010

February 23 ${ }^{\text {rd }}, 2003$

Prepared for the United States

Department of Energy

Under cooperative agreement

\#DE-FC36-99G010449 


\section{Technical Summary}

A body of work was performed in which the feasibility of photocatalytically decomposing water into its constituent elements using a dual bed, or modular photosystem, under solar radiation was investigated. The system envisioned consists of two modules, each consisting of a shallow, flat, sealed container, in which microscopic photocatalytic particles are immobilized. The photocatalysts absorb light, generating free electrons and lattice vacancy holes, which are capable of performing reductive and oxidative chemistry, respectively. The photocatalysts would be chosen as to whether they specifically promote $\mathrm{H}_{2}$ or $\mathrm{O}_{2}$ evolution in their respective containers. An aqueous solution containing a redox mediator is pumped between the two chambers in order to transfer electron equivalents from one reaction to the other.

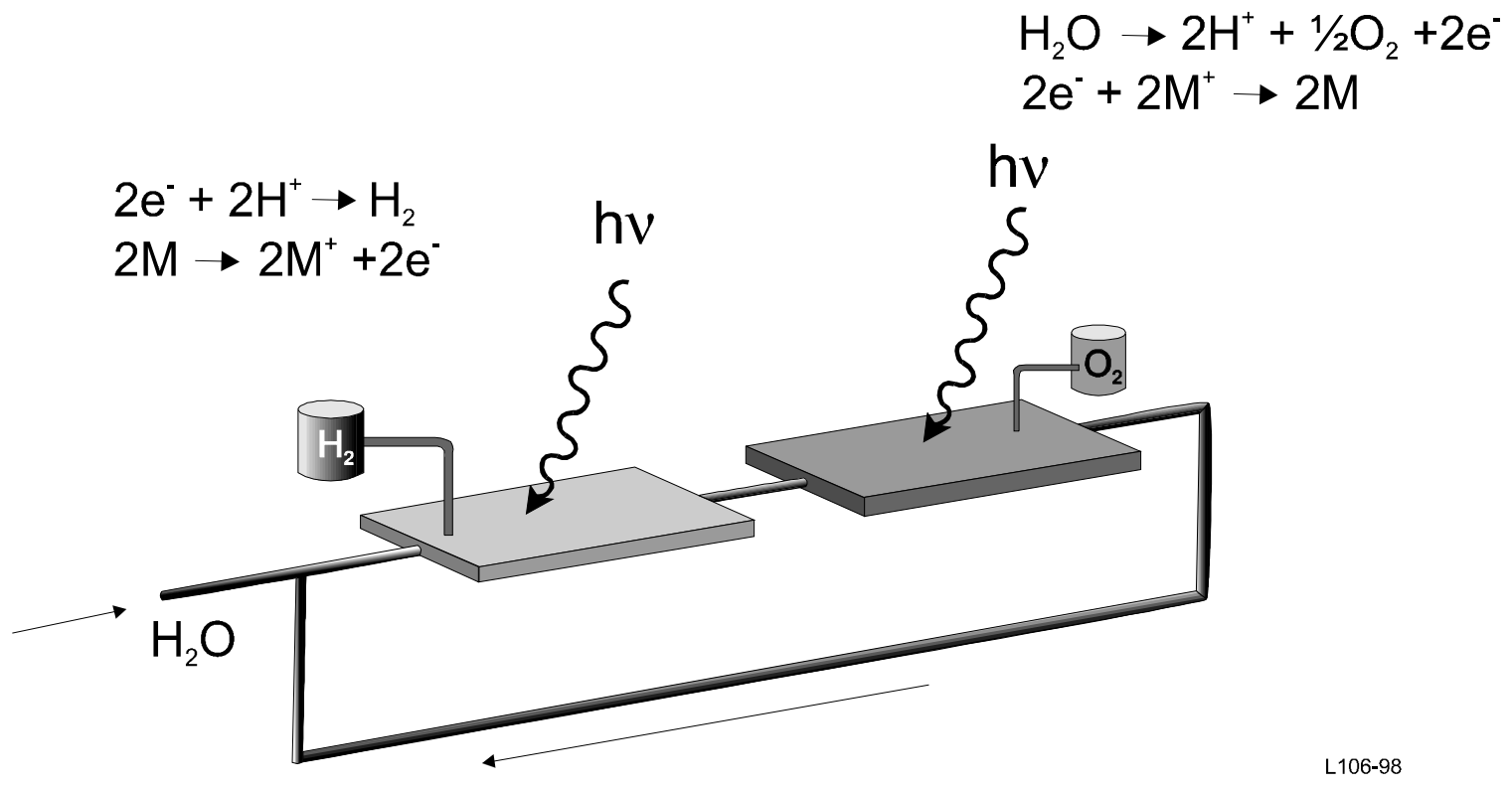

The photosystem would feature:

- separate evolution of $\mathrm{H}_{2}$ and $\mathrm{O}_{2}$

- potentially higher utilization of the solar spectrum, since the two light-absorbing modules will be able to use more abundant, lower energy photons.

- cheap reagents, photocatalysts, and construction materials, plus minimal processing result in a low cost module.

This is the final project report on Phase II of the cooperative agreement. The objective of this phase was to perform R\&D tasks that would enable engineering and economic analyses of the technology. Our preliminary determination, based on materials costs, was that the dual bed could produce $\mathrm{H}_{2}$ at $\$ 13 / \mathrm{mBtu}$ if the solar-to- $\mathrm{H}_{2}$ energy conversion efficiency of the system is $8 \%$. 
The early work on this project concentrated on traditional inorganic semiconductor powders as photocatalysts, such as $\mathrm{TiO}_{2}$ and $\mathrm{InP}$. While $\mathrm{H}_{2}$ and $\mathrm{O}_{2}$ evolution was observed, it was realized that these materials could not reach the $8 \%$ efficiency objective. With a band gap energy of $3.0 \mathrm{eV}, \mathrm{TiO}_{2}$ did not absorb enough of the solar spectrum. While InP had a better suited band gap energy of $1.3 \mathrm{eV}$, it was subject to corrosion in the alkaline electrolyte.

It was decided at that point to consider organic semiconductors. While limited photoconductivity in the solid state was a definite weakness of the pigments, it was thought that it could be overcome with their high extinction coefficients in the visible range, plus being able to utilize the synthetic opportunities of organic dyestuff chemistry. A combination of molecular orbital calculations, voltammetric wave analysis, and gas phase ultraviolet photoelectron analysis enabled us to define what molecular structures would make the best photocatalysts. We subsequently designed, synthesized, and tested a number of compounds that appeared to have optimum characteristics. The absorption spectra of the pigments plus their abilities to oxidize or reduce water went together to make complementary pairings that would absorb most of the visible spectrum while performing net water-splitting.

The best pairing was made from an alkyl chain derivative of perylene diimide as an $\mathrm{O}_{2^{-}}$ evolving photocatalyst and copper phthalocyanine as the $\mathrm{H}_{2}$-evolving photocatalyst. The perylene was modified with an Ir co-catalyst, while the phthalocyanine was modified with a $1 \%$ dispersion of Pt. The basic criterion of dual bed function was satisfied, i.e., visible light $(\lambda>400 \mathrm{~nm})$ illumination of the perylene dispersion evolved $\mathrm{O}_{2}$, while the copper phthalocyanine dispersion evolved $\mathrm{H}_{2}$. However, the yields were quite low, on order of 10 's of microliters in a 6-hour experiment. It was decided that using the pigments as dye sensitizers may be the best way to employ their good light-absorbing characteristics.

Another limitation observed was that $\mathrm{O}_{2}$ evolution could only be driven if the redox mediator was predominately present in the reduced form, while $\mathrm{H}_{2}$ evolution could only be observed only when the oxidized form was the majority species. In order for dual bed systems to operate properly in a cyclical manner, the Ox/Red ratio in the circulating fluid should fall as it passes through the $\mathrm{O}_{2}$-evolving chamber, and rise as it passes through the $\mathrm{H}_{2}$-evolving chamber. It was exceedingly difficult to measure significant gas evolution in systems where the $\mathrm{Ox} /$ Red ration was unity.

As a result, systems studies were performed. An electrochemical equivalent of a dual bed cell was constructed and tested using a dual channel power supply and twin interdigitated nickel wire networks. Redox mediators representing a range of electrochemical reversibilities (potassium ferro/ferricyanide as a reversible couple, potassium iodate/iodide as a quasi-reversible couple, and benzhydroquinone/benzoquinone as an irreversible couple) were tested. The coulombic efficiency of the system $\left(\mathrm{H}_{2}\right.$ gas evolved in comparison to integrated current, or charge) was found to fall for the reversible couple as the Ox form of the mediator rose with time, while it remained high for the irreversible system. This work pointed out the need to develop more sophisticated redox mediators, which would possess characteristics that would discourage back-reaction. 


\section{TABLE OF CONTENTS}

SECTION 1: BACKGROUND STUDIES ON THE ALKALINE IODATE REDOX MEDIATOR

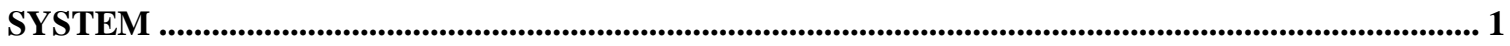

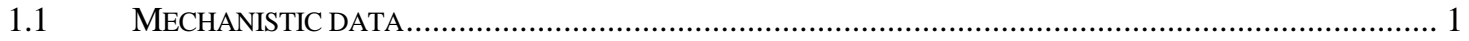

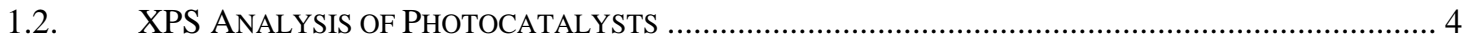

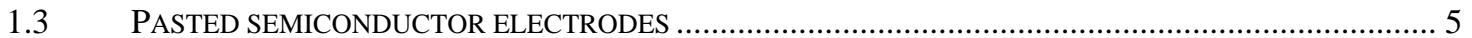

SECTION 2: ORGANIC PIGMENTS AS SEMICONDUCTOR ELECTRODES ...................................... 6

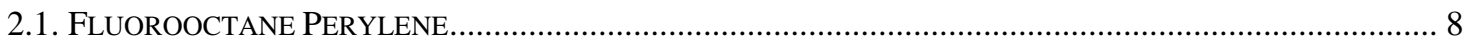

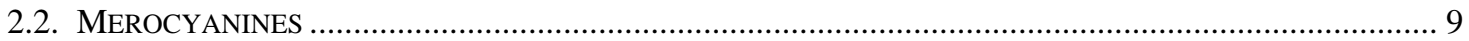

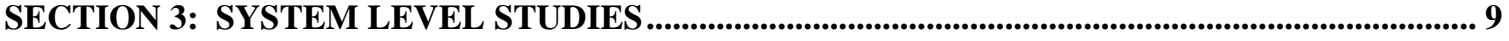

SECTION 4. PARTICIPATION IN INTERNATIONAL ENERGY AGENCY ANNEX ON

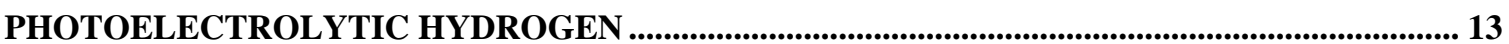

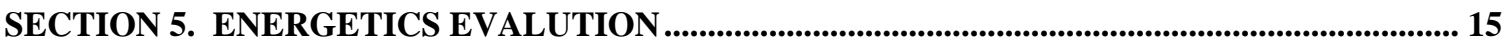

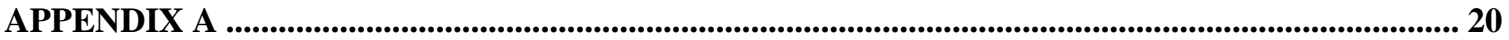

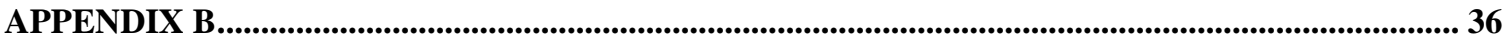




\section{Section 1: Background Studies on the Alkaline Iodate Redox Mediator System}

\subsection{Mechanistic data}

The working fluid in the dual bed system consists of an aqueous solution containing a redox mediator. At any given point along the circulatory system, in the steady state, there will be a fixed ratio of Ox to Red. Our best choice to date to serve as redox mediator in the dual bed system is the iodate/iodide redox couple. Iodate ion, $\mathrm{IO}_{3}{ }^{-}$is the oxidized form, and iodide ion, $\mathrm{I}^{-}$, is the reduced form. Our early work showed that for this couple to maintain thermodynamic stability and to facilitate the kinetics of $\mathrm{O}_{2}$ evolution, the $\mathrm{pH}$ must be high, on order of 13,14 , or higher. While we have performed many experiments with this couple, basic considerations of operating parameters have yet to be optimized (photocatalyst concentration, mediator concentration, operating temperature, light intensity dependence, etc).

Consequently, a customized water-jacketed photocell was ordered from Labglass. It had 4 ports designed into it: gas in, gas out, temperature probe, and one extra for other tasks, such as gas sampling, $\mathrm{pH}$ measurement, etc.

Our first objective was to decide what type of measurement system should be used to quantity the gas evolution. The two basic approaches are: 1) volumetric measurement, utilizing an inverted graduated cylinder; and 2) gas chromatographic, where a sampling of the headspace above a photocatalyst suspension is injected, separated into components, and quantified. Figure 1 shows the dependence of $\mathrm{O}_{2}$ evolution on the loading, or concentration, of $1 \%$ Ir-modified $\mathrm{TiO}_{2}$ photocatalyst. Two curves are shown, one for purely volumetric measurement, and one derived from $1.0 \mathrm{ml}$ injections into a gas chromatograph. The two curves track each other, but the volumetric measurement is consistently higher. We believe the difference is due to an error based on pressure/volume-type expansion in the photocell. As the Xe lamp radiation continuously enters the cell, scattered and absorbed light begins to generate heat, which in turn heats the gas over the sample, plus promoting gas evolution due to lower solubility of the gases as temperature increases. This is manifested in the graduated cylinder gas collector as an enhanced gas evolution. Hence, the gas chromatographic method was deemed to be more accurate.

The other aspect of Figure 1 is, of course, the photocatalyst concentration dependence itself. It was observed via either method that the ability of the photocatalyst to evolve $\mathrm{O}_{2}$ leveled out at a density of $\sim 2 \mathrm{mg} / \mathrm{ml}$.

An iodate concentration dependence was completed and turned out to be surprisingly nonlinear. This result is shown in Figure 2. Note that the X-axis is logarithmic with respect to concentration, so that there is an ever-diminishing effect of iodate concentration on performance. This may be due to an adsorption effect of the iodate salt.

A pH-dependence was also performed. $\mathrm{O}_{2}$ evolution was flat down to $\mathrm{pH} 11$ and then fell off beyond that point. We could not go any lower than $\mathrm{pH} 8$ because the iodate/iodide couple becomes unstable below that value. 


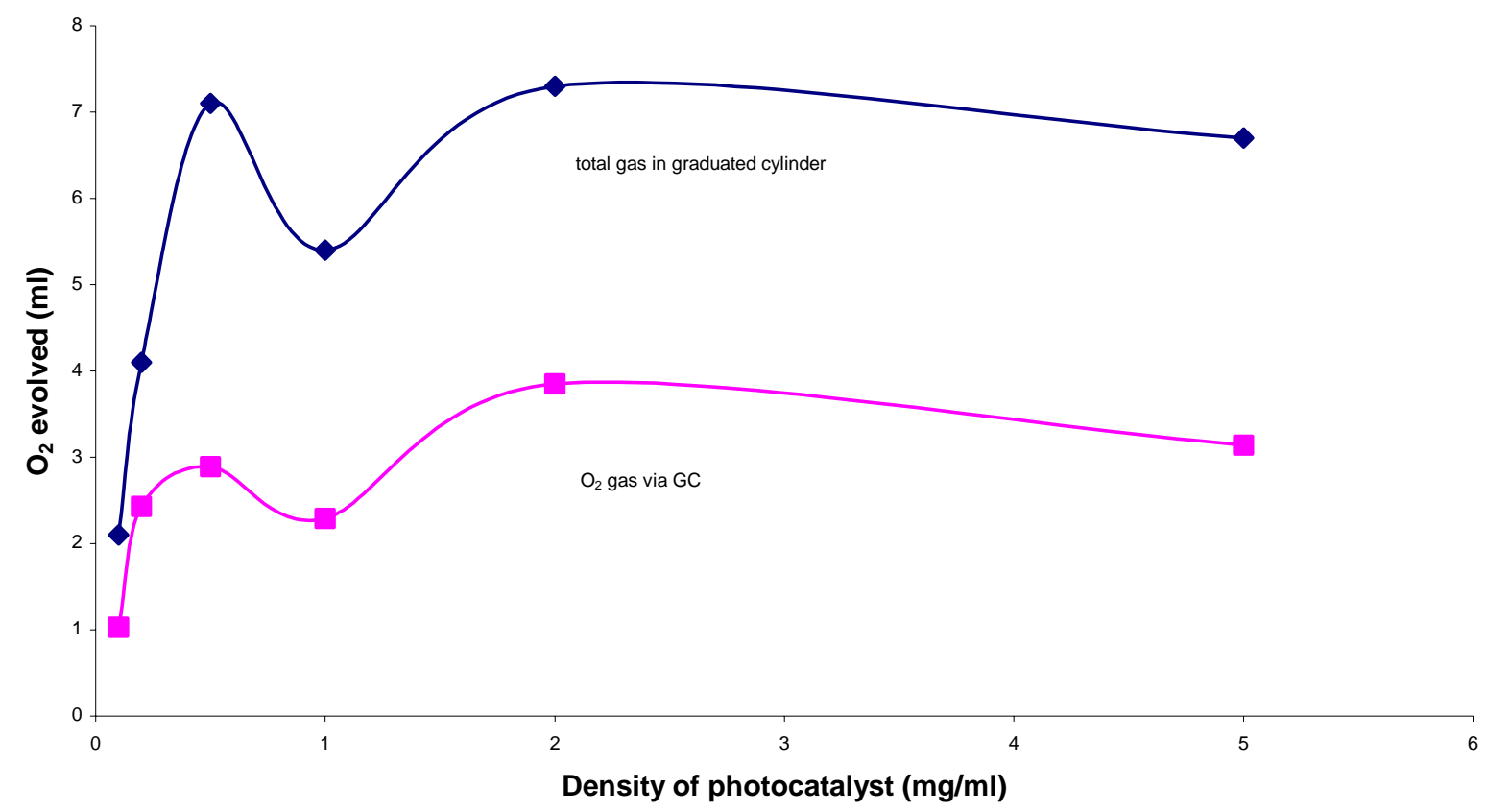

Figure 1. Measurement of thermal expansion effect on gas evolution

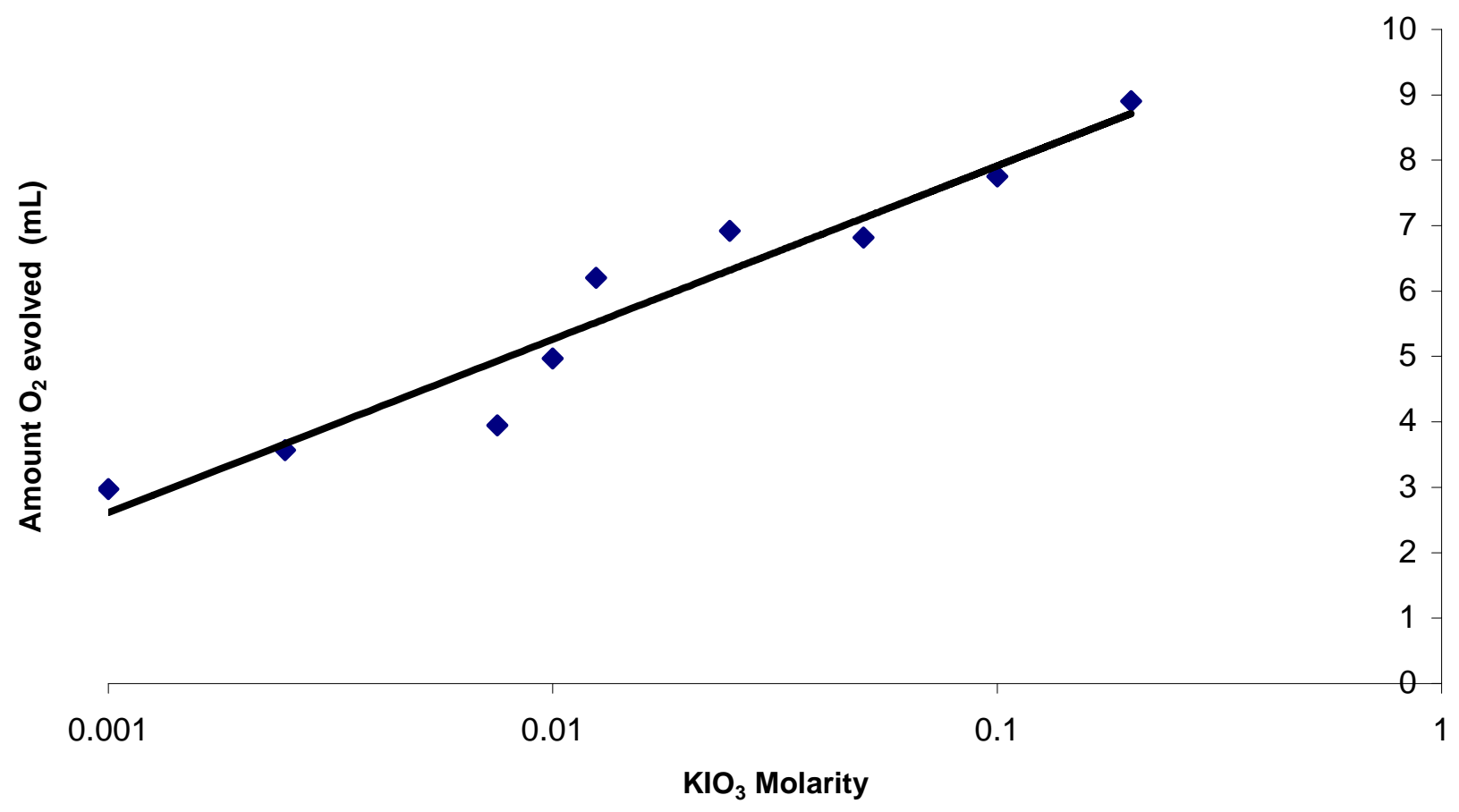

Figure 2. Dependence of $\mathrm{O}_{2}$ evolution on concentration of redox mediator. 
Overall, the $\mathrm{Ir}-\mathrm{TiO}_{2} /$ iodate system behavior may be explainable as rate control by iodate adsorption. Corresponding adsorption experiments where we tried to measure iodate uptake as a function of background iodate concentration were performed. At first we attempted to monitor the system using the iodate UV absorbance peak at $220 \mathrm{~nm}$, but there were too many interferences; we then switched to an iodate acidification procedure where iodate is converted to iodide, whose spectral signal is much larger and in the visible range $(450 \mathrm{~nm})$ where there are fewer interference. The difficulty with this procedure is that one must add at least an 8-fold excess of iodide ion to make sure the conproportionation goes to completion, plus ensure quantitative production of triiodide ion, which absorbs at $350 \mathrm{~nm}$.

For the $\mathrm{Ir}_{-} \mathrm{TiO}_{2}$ work, we have settled on a 10 -fold excess of iodide ion with respect to iodate to achieve a quantitative conversion to triiodide ion. Adsorption experiments on Ir- $\mathrm{TiO}_{2}$ inexplicably gave a higher triiodide signal than the control experiment with no photocatalyst to adsorb to. Plain $\mathrm{TiO}_{2}$ showed net adsorption, however. We finally abandoned spectroscopic determination of iodate adsorption entirely and resorted to traditional iodometry. These results suggest a linear dependence between iodate concentration and adsorption, so that adsorption cannot explain the nonlinear $\mathrm{O}_{2}$ evolution behavior.

The water-jacketed test cell enabled us to perform a temperature dependence of $\mathrm{O}_{2}$ evolution as well. The temperature dependence is shown in Figure 3. We obtained a negative temperature dependence, counterintuitive to what we had expected.

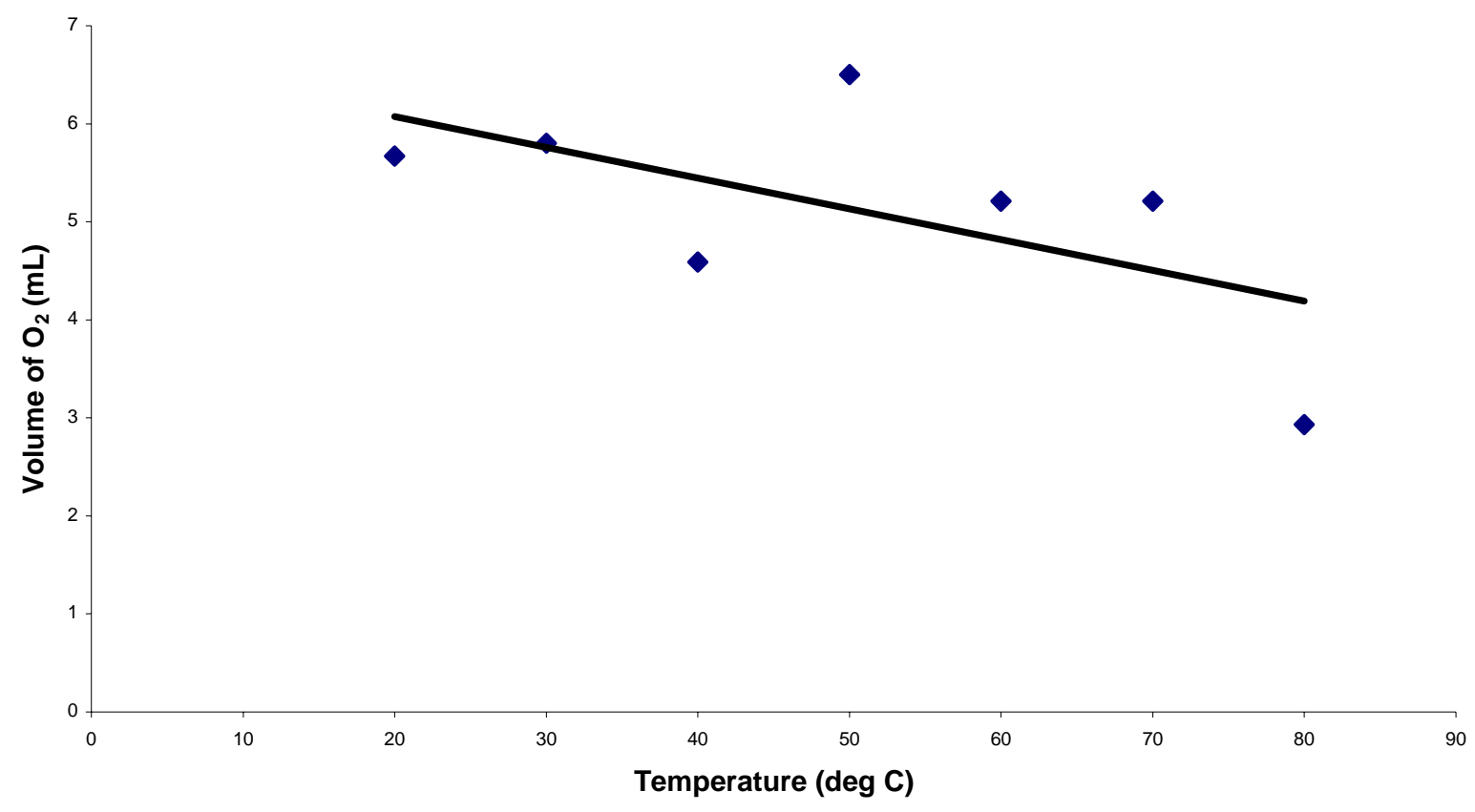

Figure 3. Temperature dependence of photocatalytic $\mathrm{O}_{2}$ evolution 
Basic theory of solid state semiconductivity states that electrical conductivity should rise with temperature increase. Likewise, chemical rates constants generally increase with temperature, as kinetic activation barriers are more easily surmounted. This dependence points once again at adsorption of iodate ion as an important factor. While the adsorption isotherm measurements made above were inconclusive, it is nevertheless clear that iodate adsorption will fall as temperature rises, so that if $\mathrm{IO}_{3}{ }^{-}$(ads) is the predominate electron acceptor species, desorbing iodate ion accompanying temperature rise could reduce the rate of reaction.

An intensity dependence was performed using a sequence of neutral density filters. Results are shown in Figure 4 below. A linear correlation between $\mathrm{O}_{2}$ evolution and intensity was found, consistent with what is typically observed for $\mathrm{TiO}_{2}$.

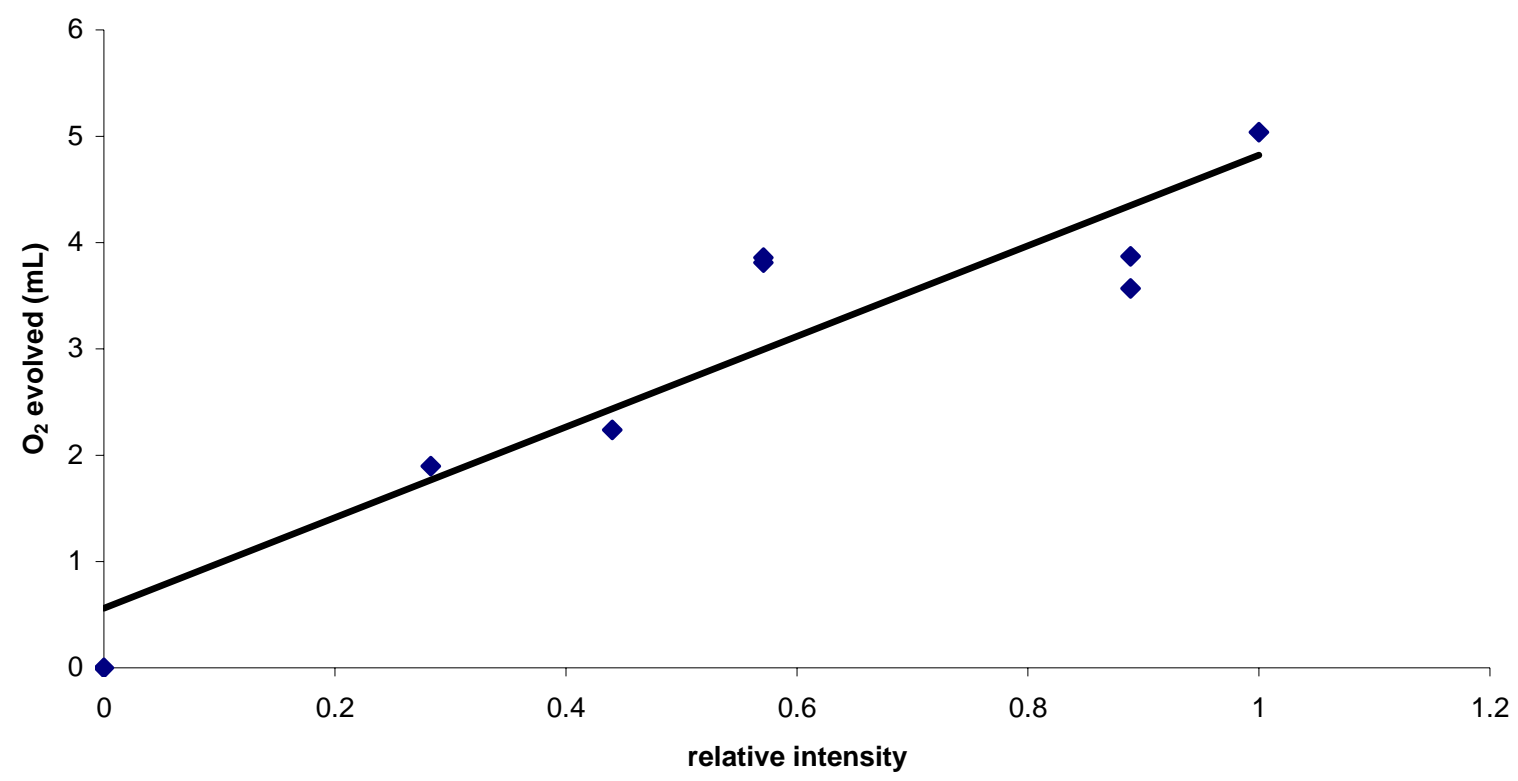

Figure 4. Light intensity effect on $\mathrm{O}_{2}$ evolution.

\subsection{XPS Analysis of Photocatalysts}

Peak shift data in X-ray photoelectron spectra can often be used to determine the oxidation state of the element in question. Our main interest was in understanding the oxidation state of the Ir that we deposit as a co-catalyst on $\mathrm{TiO}_{2}$. It was giving our best performance in terms of gas evolution, and so we had great interest in identifying the state of the deposited Ir.

The University of Central Florida maintains the Materials Characterization Facility, MCF, a central facility where various high vacuum surface analysis equipments are kept and maintained for the use of the university at large. Our particular interest was to utilize the valency-dependent energy shifts of primary electron emission to determine the oxidation state of our various co-catalysts. 
The evidence we had obtained about the Ir up until then had been conflicting. The borohydride reduction method used to deposit the Ir was intended to produce the metallic, or zerovalent, state. However, it was acknowledged that the procedure did not work as cleanly as had been accomplished with platinum salts. The Ir salt used was iridium trichloride, $\mathrm{IrCl}_{3}$. It would dissolve with great difficulty in alkaline solution; addition of borohydride did not significantly change the appearance of the solution. Nevertheless, it was clear that some form of the iridium was being deposited on the TiO2, as the normally bright white oxide would take on a blue to gray appearance. Also, the ability to evolve $\mathrm{O}_{2}$ would increase by several-fold. In short, it was not clear whether the borohydride was successfully reducing the iridium salt to the elemental state, or that the salt was simply adsorbing to the titania surface, and retaining its original oxidation state $(+3)$.

Various X-ray photoelectron analytical techniques were attempted. It was immediately apparent that a simple peak shift analysis would be inadequate. First, the charging correction had to be determined. Because the oxide sample was electronically insulating, steady electron emission from the sample can generate a surface charge which represents a voltage barrier. The electron analyzer then measures an electron energy that is less than it should be. Clearly it was very important to obtain charge-corrected data for $\mathrm{Ir}^{-\mathrm{TiO}_{2}}$, especially since the charge shift correction is oftentimes larger than the oxidation state shift of the element of interest.

An even greater difficulty had to do with spectral interference on the absorption peak of interest. The predominate transition for Ir is the Ir $4 \mathrm{f}$, which occurs as a doublet, corresponding to the $5 / 2$ and $7 / 2$ spin states. This peak is overlapped by the Ti 3s transition, which of course present in much greater abundance. We took spectra of pure $\mathrm{TiO}_{2}$ standards to get a Ti 3s baseline to subtract from Ir-TiO 2 , but could not resolve the Ir transition. The other problem was that while $\mathrm{TiO}_{2}$ had 2 peaks and $\mathrm{Ir}-\mathrm{TiO}_{2}$ had 3 in the $60 \mathrm{eV}$ range, none of them matched up, so that it still was not clear which peak belong to Ir.

We also tried to look at a chemical shift of the Ir $4 \mathrm{~d}$ transition. It was weaker than the $4 \mathrm{f}$, but it did not interfere with any Ti transition. It did, however, interfere with C 1s, so that we could not use carbon tape as a substrate for the $\mathrm{Ir}-\mathrm{TiO}_{2}$ powder. Switching to an indium foil substrate was also unsuccessful. Finally, the XPS machine's sputter gun broke, leaving an indeterminate amount of time before we could go back to the Ir oxidation state problem. At that point, we had to give up trying to use $\mathrm{X}$-ray photoelectron spectroscopy to obtain the oxidation state of Ir in our $\mathrm{Ir}^{-\mathrm{TiO}_{2}}$ formulations. We may later try to use voltammetry to look for a reduction current on films of the material, which would occur only if an oxide were present. At this point, we believe that the Ir exists as a surface oxide. Most of our preparations of the photocatalyst have a distinct bluish tint, characteristic of $\mathrm{IrO}_{2}$.

\subsection{Pasted semiconductor electrodes}

At the September, 2001, IEA meeting (Section IV), we learned of a novel technique for preparing semiconductor electrodes. Instead of going through a tedious chemical vapor deposition or sol-gel procedure, the researchers were simply spraying a slurry of 
photocatalyst onto a fluorine-doped tin oxide electrode and then pressing in a hot press. These electrodes were purportedly just as good as those made by more sophisticated means.

We attempted this procedure using $\mathrm{TiO}_{2}, \mathrm{Fe}_{2} \mathrm{O}_{2}, \mathrm{ZnO}$, and some other available semiconductor powders. The three photocatalysts mentioned above worked rather well; other photocatalysts did not work as well, ostensibly because the particle size was too great. We also looked at pressing methods of affixing $\mathrm{TiO}_{2}$ to glass substrates for nonvoltammetric experiments. We gained access to a Dektak profilometer to measure the thickness of our pasted MOx films. There was some shrinkage, but we were able to show a uniform film in the 10's of micron range. Despite some early success, we ultimately abandoned the cold pressing technique after breaking too many of our $\mathrm{F}_{-}-\mathrm{SnO}_{2}$ substrates.

\section{Section 2: Organic pigments as semiconductor electrodes}

Using semiempirical molecular orbital calculations, ultraviolet photoelectron spectroscopy, voltammetric analysis, and UV-visible spectrophotometry, a number of organic pigment compounds were identified that are good absorbers of solar radiation, and are energetically capable of performing the various photoredox processes.

We also conducted a literature search on organic photoconductive compounds to see if there were any classes of compounds that we were overlooking. After a thorough effort, if was concluded that we are already working with the best compounds, i.e., the perylenes, phthalocyanines, quinacridones, and indanthrones are the leading materials in this area.

Voltammograms in the light and dark were obtained for thick film organic pigments. The intent was to observe a film thickness effect; thick films should exhibit essentially an Ohm's Law plot, while thin ones would be dominated by nonlinear faradaic activity. The other possibility for thin films was that the In-doped $\mathrm{SnO}_{2}$ conductive substrate would show through and exhibit its own voltammetry. A photoeffect was obtained, but it was superimposed upon a significant dark background.

A modest photosensitization effect was achieved using $\mathrm{H}_{2} \mathrm{Q}$ in organic electrolyte (acetonitrile), but its current-voltage behavior was complicated, possibly due to a mixture of protonation and nonprotonation electrochemistry. $\mathrm{F}-\mathrm{SnO}_{2}$ showed n-type rectification for $\mathrm{H}_{2} \mathrm{Q}$ under $>400 \mathrm{~nm}$ illumination; however, in the presence of quinacridone, one of our favorite pigments, it was eliminated. $\mathrm{TiO}_{2}$ on $\mathrm{F}-\mathrm{SnO}_{2}$ also eliminated rectification.

We also attempted to determine whether the redox potential of adsorbed dyes shift with $\mathrm{pH}$. The first step is to determine what conductive substrate material gives the least complicated voltammetric background. It was difficult finding a suitable electrode support. The indium-tin oxide electrodes were acid unstable and Pt had too much background in cathodic region. Carbon cloth worked reasonably well. However, the adsorbed pigments did not seem to be electroactive at all, so we were unable to check the $\mathrm{pH}$ dependence of redox wave. 
After performing a large number of voltammetric experiments, we returned to the photocatalytic gas evolution trials. The data associated with these tests are shown in Table 1 below. Both modules by themselves were shown to work, selectively evolving either $\mathrm{H}_{2}$ or $\mathrm{O}_{2}$ while respectively oxidizing or reducing the iodate/iodide redox mediator. We were able to obtain tiny amounts of gas (a few microliters) when the chemical potential of the solution, as determined by the concentration ratio of the oxidized and reduced forms of the mediator, were identical for both modules, proving the necessary condition that the effluent of one module can be acted on by the other. However, greater amounts could be obtained when the Ox form of the mediator alone was supplied to O2-evolving system, and the Red form supplied to the H2-evolving system.

Immobilized perylene and indanthrone films were tested. They were prepared via spraying of a LAPS solution ( $\mathrm{AlCl}_{3}$ solution of methylene chloride and nitromethane). The illumination source was a $1.0 \mathrm{~kW}$ Xe lamp with $400 \mathrm{~nm}$ filter. The measured $\mathrm{O}_{2}$ yield was in range of 10's of microliters. $\mathrm{I}_{2}$-doping to improve conductivity was unsuccessful. For the $\mathrm{O}_{2}$-evolving module, the best photocatalyst material proved to be a perylene diimide, while the best material for $\mathrm{H}_{2}$-evolution was copper phthalocyanine. While the LAPS method was vital in preparing some samples, it was deleterious in others, as with copper phthalocyanine, for example.

We continued to look at variations of our alkaline/iodide photocatalytic system to determine where the rate limited steps in the process lie. EDTA, a well known multidentate chelating agent and irreversible electron donor, was used to observe $\mathrm{H}_{2}$ evolution from a Pt-CuPc photocatalyst. Only a few microliters of $\mathrm{H}_{2}$ were obtained, or about the same as when a reversible redox agent is employed. This would imply that the rate of electron transfer to the redox mediator in solution is not rate limiting.

Table 1. Gas Evolution Data for Immobilized Dispersions of Organic Pigments

\begin{tabular}{|c|c|c|c|c|c|}
\hline Photocatalyst & Redox agent & $\begin{array}{c}\text { Initial Ox:Red } \\
\text { ratio }\end{array}$ & $\begin{array}{l}\text { UV cut-off } \\
\text { filter }\end{array}$ & $H 2, \mu L$ & $02, \mu L$ \\
\hline Perylene diimide & $\mathrm{IO}_{3}^{-}$ & $1: 0$ & $\mathbf{Y}$ & - & 32 \\
\hline Perylene diimide & $\mathbf{I}^{-}$ & $0: 1$ & $\mathbf{N}$ & 17 & - \\
\hline Indanthrone & $\mathrm{IO}_{3}^{-}$ & $1: 0$ & $\mathbf{Y}$ & - & 45 \\
\hline Indanthrone & $\mathbf{I}^{-}$ & $0: 1$ & $\mathbf{N}$ & 146 & - \\
\hline CuPc & $\mathbf{I}^{-}$ & $0: 1$ & $\mathbf{N}$ & 113 & - \\
\hline CuPc & $\mathbf{I}^{-}$ & $1: 1$ & $\mathbf{N}$ & 90 & - \\
\hline CuPc & $\mathbf{I}^{-}$ & $1: 1$ & $\mathbf{Y}$ & 10 & - \\
\hline CuPc & EDTA & $0: 1$ & $\mathbf{Y}$ & 5.3 & - \\
\hline CuPc & EDTA + I- & $0: 1$ & $\mathbf{Y}$ & 5.0 & - \\
\hline CuPc & $\mathrm{K}_{4} \mathrm{Fe}(\mathrm{CN})_{6}$ & $0: 1$ & $\mathbf{Y}$ & 3.9 & - \\
\hline NiPc & $\mathbf{I}^{-}$ & $0: 1$ & $\mathbf{N}$ & 23 & - \\
\hline VOPc & $\mathbf{I}^{-}$ & $0: 1$ & $\mathbf{N}$ & 26 & - \\
\hline quinacridone & $\mathbf{I}^{-}$ & $0: 1$ & $\mathbf{N}$ & 116 & - \\
\hline quinacridone & $\mathbf{I}^{-}$ & $1: 1$ & $\mathbf{Y}$ & 8 & - \\
\hline
\end{tabular}

1.0 M NaOH electrolyte, $0.2 \mathrm{M}$ mediator concentration

6.0 h Xe lamp exposure 


\subsection{Fluorooctane Perylene}

After doing many molecular orbital calculations and voltammetric measurements, we found that derivatives of perylene reliably possessed valence band edges that were positive enough on the voltage scale to oxidize water. This led us to consider making our own customized perylene derivatives.

About the same time, an article in Nature (vol 404, 30 March 2000) described an organic semiconductor that had increased electron mobility when a fluorinated sidechain was added. The semiconductor compound, naphthalenetetracarboxylic diimide, was analogous to the perylene diimide that we had been investigating for oxidative water splitting. We, therefore, became interested in the influence that would result from fluorinated N,N'-alkyl groups on the perylene compound.

Since perfluorinated alkanes with a terminal bromine were easily obtainable, it was hoped that the literature would outline a method for N-alkylation of the perylene diimide parent compound, Scheme 1. An extensive review of the literature led us to US Patent 6,084,099 by Hackmann, et al:

Scheme 1.

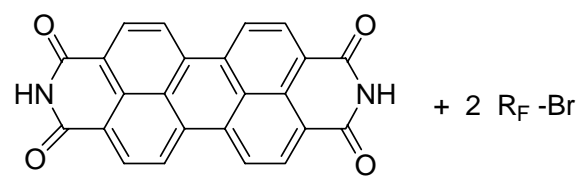

$\underline{1}$

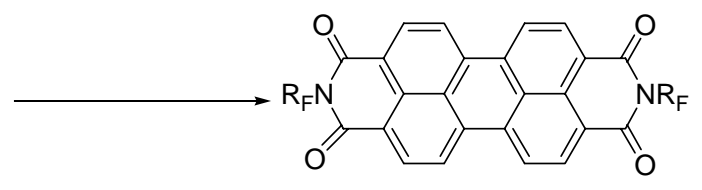

$\underline{2}$

Unfortunately, there were several problems. A major problem was that nucleophilic substitutions involving perfluorinated compounds are known to be sluggish. It was believed that a fluorinated compound with a methylene spacer would be more likely to react in the above Gabriel synthesis. While the fluorinated bromide with a methylene spacer was not readily available, the corresponding alcohol was available and conversion was thought to be possible using a standard acid catalyzed $\mathrm{S}_{\mathrm{N} 2}$ reaction.

If either the alcohol-to-bromide conversion or the Gabriel synthesis was unsuccessful, the more common means of forming an N,N'-alkyl diimide was to start with the anhydride and react it with the amine, as shown in Scheme 2:

Scheme 2.

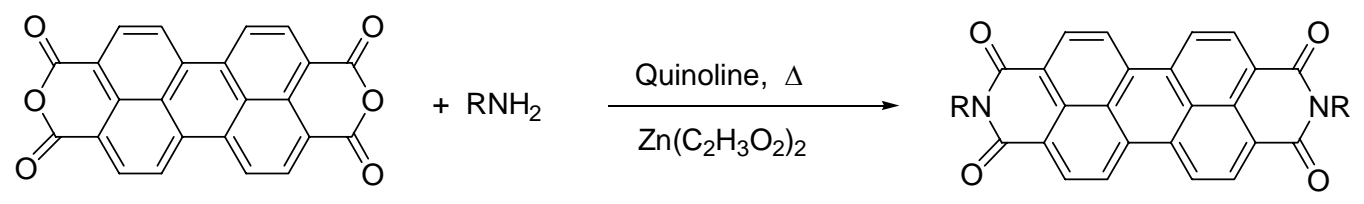


The primary difficulty with synthesizing the compound in this manner was the availability of the required fluorinated amine. Because we believed that converting the alcohol to the bromide would be easier than fluorinating the required amine, Scheme 1 was attempted first.

Ultimately, it was found that the direct reaction between the perfluoroalkyl alcohol and $\mathrm{HBr}$ did not work nearly as well in comparison to the reaction where a nonfluorinated alcohol is used, so that the desired fluorinated bromide reagent remained elusive.

Fortunately, a source was found to obtain a fluorinated amine appropriate for use in our back-up plan, forming the N,N'-alkyl diimide by starting with the dianhydride and reacting it with the amine. The amine was obtained and the reaction was run. Preliminary work-up and analysis of the product was supportive of the conversion of the dianhydride to the diimide. The product was purified via sublimation and tested for its ability to catalyze the water-splitting reaction. Results were disappointing, however, so that further work in this direction was curtailed pending review and comment by program management.

\subsection{Merocyanines}

Merocyanines are well known in the photographic community for high visible absorption and photoactivity. In comparing the energetic needs for dye sensitization in color photography versus oxidative water-splitting, we had concluded that any dye useful in photography would not be useful to us. However, for $\mathrm{H}_{2}$ evolution the opposite was true, namely, any dye useful for photography would easily have a conduction band sufficiently negative on the voltage scale to be able to reduce water and make $\mathrm{H}_{2}$.

Consequently, two merocyanines were ordered, one carboxylated, one not. The carboxylation was added because other research groups working on dye sensitized solar cells have reported more efficient devices when a carboxyl group is present to control the orientation of the dye molecule at the solid interface.

Merocyanine films were deposited using the LAPS solution method. Stability problems were immediately apparent, ostensibly related to photoreaction with air. Moreover, the photostability of the merocyanines was so bad that films could be illuminated with the Xe lamp in ambient air, outside the aqueous environment of the photochemical cell, and still undergo rapid degradation.

\section{Section 3: System Level Studies}

The pigment photolysis studies in Section 2 demonstrated that the efficiency of gas evolution was strongly dependent on the ratio of Ox to Red. That result left us concerned that the separate modular beds could not be connected to each other and achieve net water-splitting. If neither system could sustain gas evolution with a 1:1 Ox to Red ratio, then obviously neither module could convert the redox electrolyte to a chemical potential that the other could work upon. It may be necessary to augment the internally 
photogenerated chemical potentials with an externally powered electrochemical cell, as shown in Figure 5.

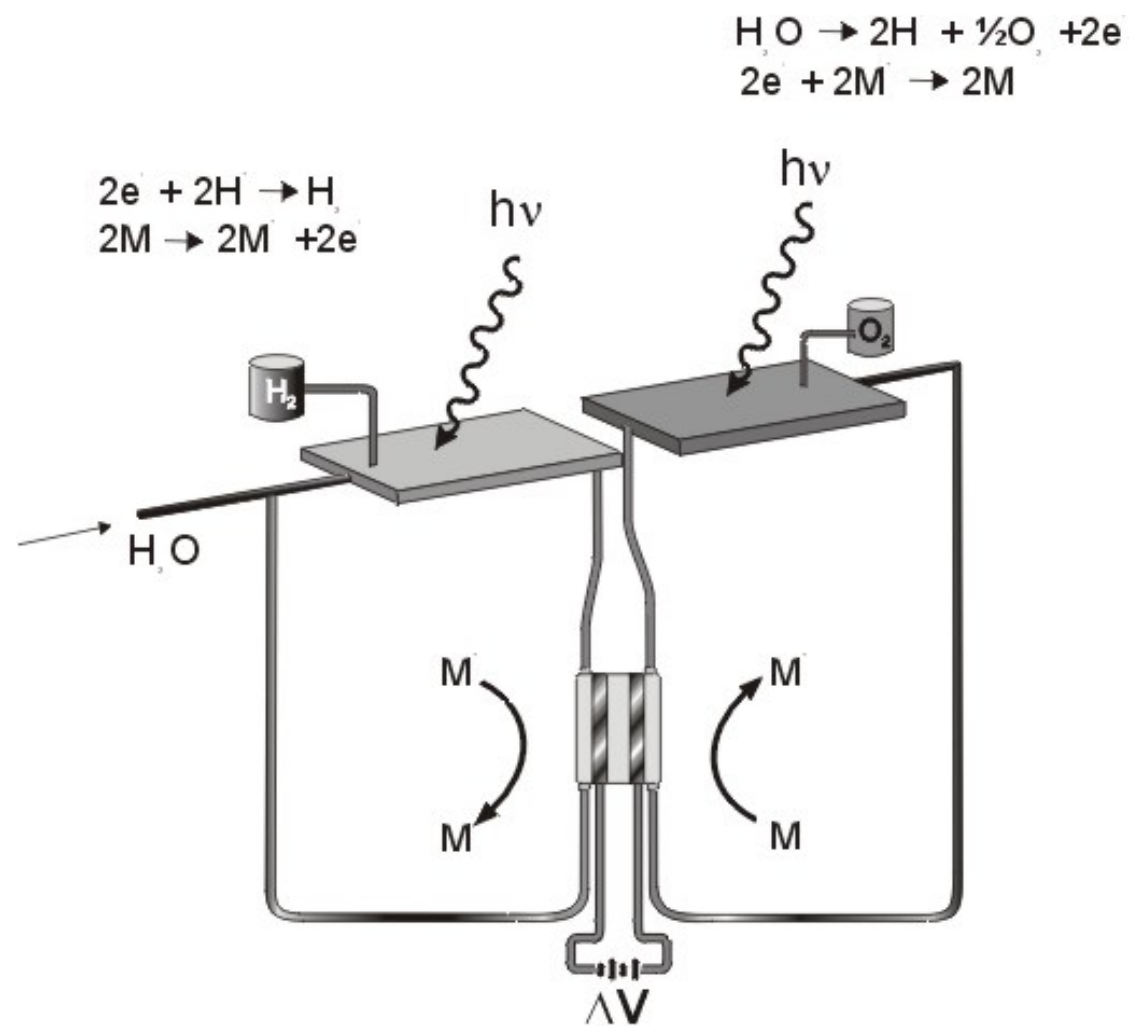

Figure 5. Schematic of dual bed cell with electrochemical assist.

It was conjectured that the electrochemical reversibility of the redox mediator was a major determinant in how far the Ox/Red ratio could be photochemically driven. Therefore, we began a systems studies effort, where we looked at the effect of reversible versus irreversible redox couples

as redox mediators in dual bed systems.

In order to test the redox electrochemistry separately from the photochemistry, we constructed an electrochemical equivalent of the dual bed cell. Modules were constructed by stringing two strands of Ni wire along the rows in a piece of perfboard in an alternating pattern, so that the end result was a somewhat macroscopic interdigitated array of wire electrodes. A voltage could be applied across the two wires arrays to simulate the generation of localized photopotentials as is thought to occur in the photocatalyst powders. The negatively polarized set of wires would evolve H2, while the positive set would oxidize the Red form of the redox mediator. Alternatively, the positively polarized set of wires would evolve $\mathrm{O}_{2}$, while the negative set would reduce the Ox form of the redox mediator. In Figure 6, a microscopic view of the perfboard array is shown. It can be seen that only one set of alternating wires is evolving gas, while the other set is acquiring its electron equivalents from the redox mediator. 

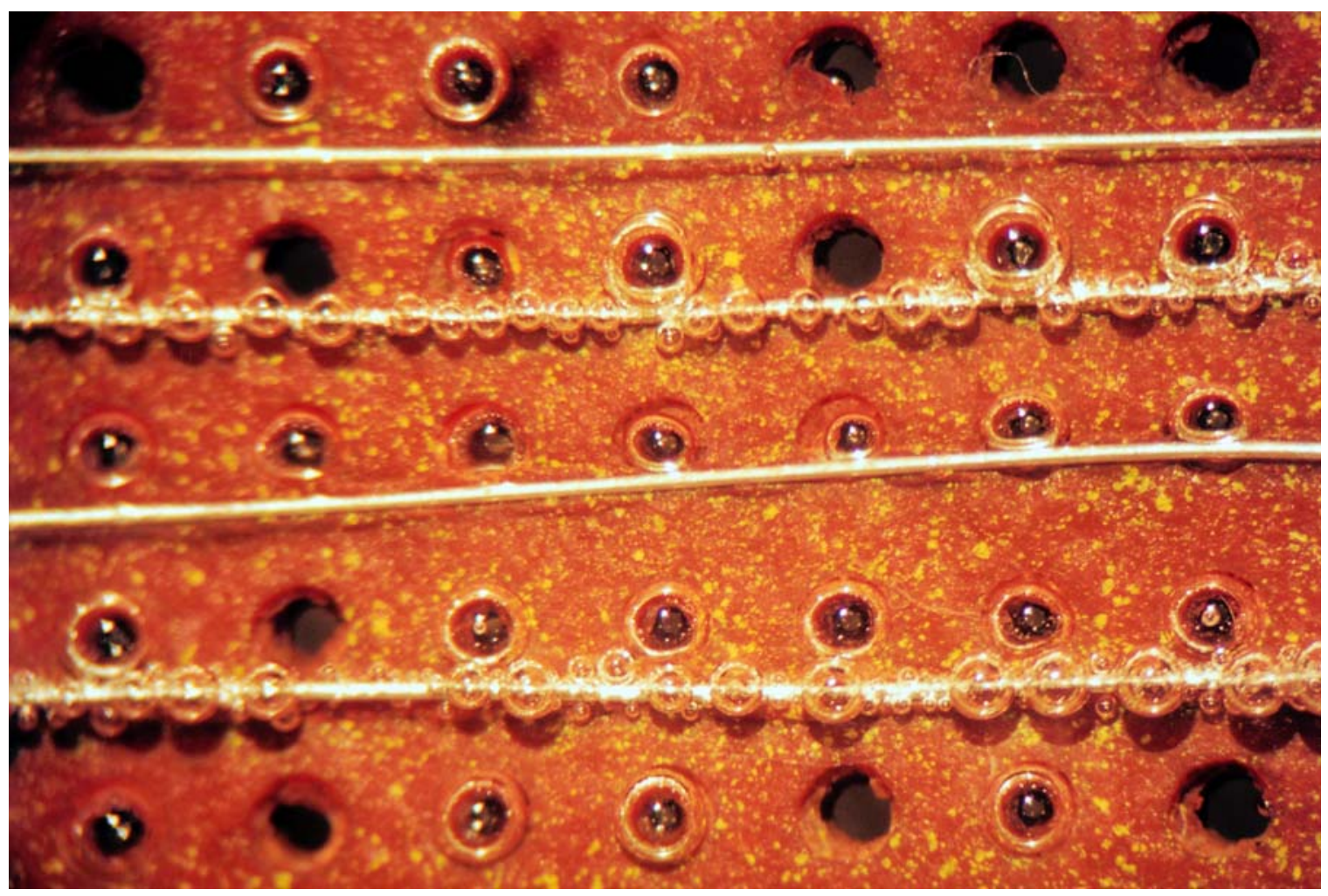

Figure 6. Microscopic view of gas evolution from a perfboard array.

The array would be placed in a flat acrylic box with ports to collect gas and supply redox electrolyte. A picture of a 5-inch square sample cell is shown in Figure 7.

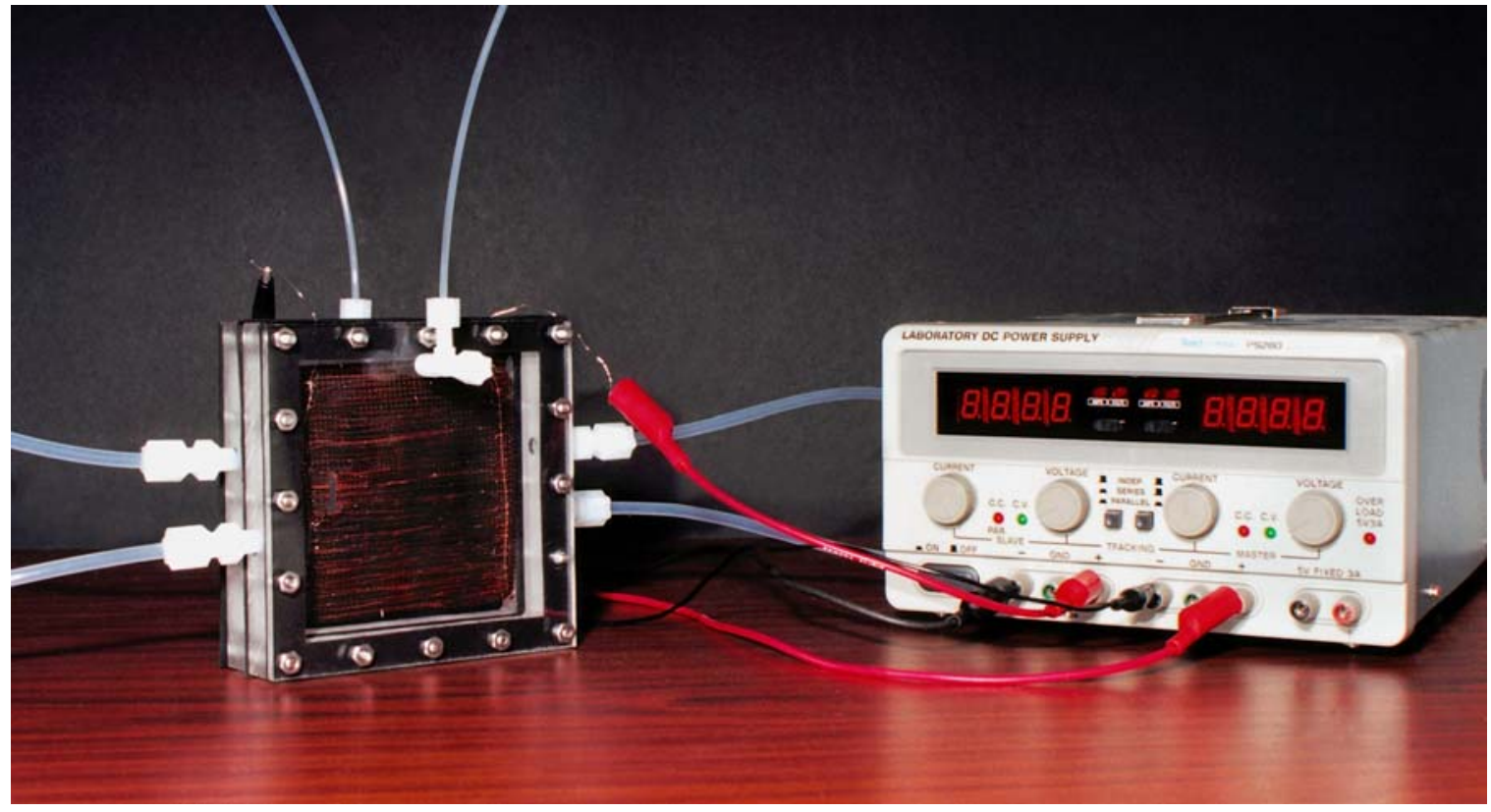

Figure 7. Picture of electrochemical dual bed cell module. 
The overall system, with two housed perfboard arrays connected to a dual channel power supply, along with gas collection apparatus and circulating pump, is shown in Figure 8. While we were able to operate each module separately, it was still problematic to run them at the same time. The biggest problem was control of gas and fluid volumes. As the pump would inject working fluid into a module, instead of flowing out the exit port at the same rate, the headspace would be pushed out into the gas collector as the module filled with solution. Since simultaneous operation of both modules was not critical to observe reversibility effects, solution of the problem was not pursued further. Possibly a series of check valves and level indicators will be necessary to organize the gas and liquid flows.

The next step was to identify redox mediators that covered a range of reversibilities. We observed that benzhydroquinone decomposed 2 /3rds per day in $1.0 \mathrm{M}$ base, but nevertheless exhibited complete irreversibility at the thermodynamic potential, making it a fairly good candidate for studying irreversibility effects. Potassium ferricyanide was identified as a reversible redox couple, while potassium iodate was thought to exhibit intermediate reversibility.

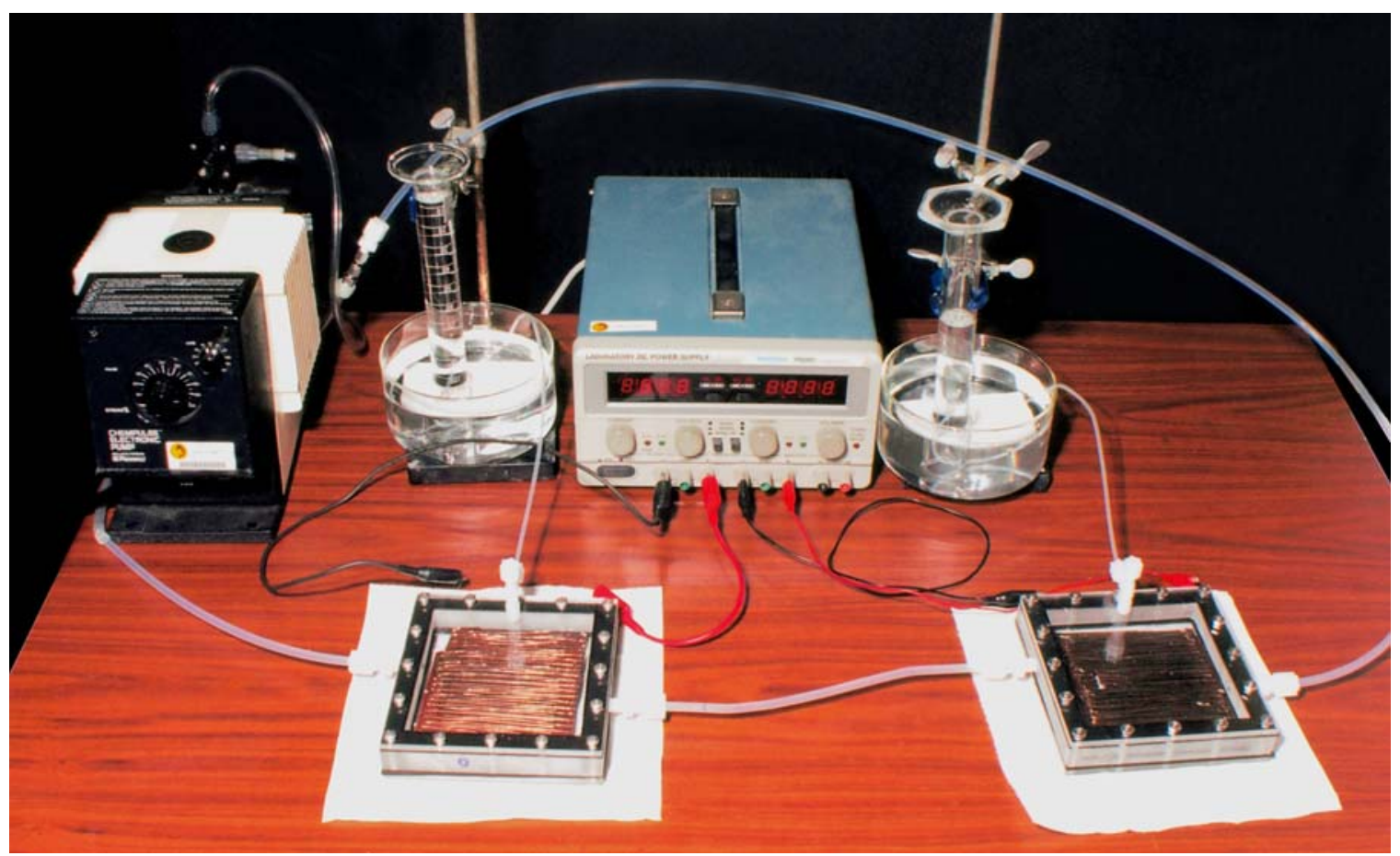

Figure 8. Picture of entire electrochemical dual bed system.

Having identified reversible, partly reversible, and irreversible redox couples on our $\mathrm{Ni}$ wire arrays, we began a series of dual bed simulations where an exhaustive electrolysis of the redox mediator was attempted. Cell current versus time was measured as well as the extent of $\mathrm{H}_{2}$ evolution. This enabled us to subsequently determine the coulombic efficiency of the cell. The relevant data are shown in Table 2 below. 
Table 2. Coulombic Efficiency ( $\eta$ ) of $\mathrm{H}_{2}$ Evolution from a Ni Wire Array Using Redox Agents Possessing Varying Degrees of Reversibility.

\begin{tabular}{c|ccccc}
\hline Redox agent & Type & $V_{\text {appl }}(V)$ & $I_{s s}(m A)$ & $\eta$ after $1 \mathrm{~h}$ & $\eta$ after $24 \mathrm{~h}$ \\
\hline $\mathrm{K}_{4}\left[\mathrm{Fe}(\mathrm{CN})_{6}\right]$ & reversible & 1.5 & 83 & $65 \%$ & $16 \%$ \\
$\mathrm{KI}$ & quasi-reversible & 1.7 & 13 & $65 \%$ & $8 \%$ \\
$\mathrm{H}_{2} \mathrm{Q}$ & irreversible & 1.2 & $6-8$ & $61 \%$ & $97 \%$ \\
$\mathrm{H}_{2} \mathrm{Q}$ & irreversible & 1.5 & 19 & $88 \%$ & $87 \%$ \\
\hline
\end{tabular}

$0.1 \mathrm{M}$ concentration of redox agent in $1.0 \mathrm{M} \mathrm{NaOH}$.

$$
\mathbf{V}_{\text {appl }}=\text { applied voltage; } \mathbf{I}_{\mathrm{ss}}=\text { steady state current }
$$

At $1.5 \mathrm{~V}$, the reversible potassium ferrocyanide couple enabled $\mathrm{H}_{2}$ evolution at only a $6 \%$ efficiency, i.e., only $6 \%$ of the cathode current was due to hydrogen production, the balance ostensibly being ferricyanide reduction. Work on the iodide system showed that $\mathrm{H}_{2}$ evolution ground to a halt after a few hours while a modest steady state current is maintained, suggesting that iodate reduction had taken over at the negative electrode. The iodide system ultimately proved to be about the same as the ferrocyanide system. After a 24 h electrolysis time, the net coulombic efficiency of $\mathrm{H}_{2}$ evolution had fallen to $\sim 16 \%$. On the other hand, benzoquinone electrolysis maintained $>90 \%$ efficiency for $\mathrm{H}_{2}$ evolution over the same period, proving the efficacy of irreversible redox couples in serving as redox mediators.

\section{Section 4. Participation in International Energy Agency Annex on Photoelectrolytic Hydrogen}

The funding for Phase II actually arrived some 5-6 months into the project period. Meanwhile, the IEA meeting was already slated to occur in Switzerland. DOE agreed to fund the trip, provided funding was ultimately approved for the project. That scenario ultimately came true.

The IEA trip to Switzerland went off as planned. It was hosted by Prof. Micheal Grätzel of the University of Lausanne. A side trip to visit Prof. Augustynski's lab at University of Geneva was also made. The presentation on our work was reasonably well received. Prof. Grätzel was particularly intrigued by our work on $\mathrm{H}_{2}$-evolving pigments. $\mathrm{He}$ suggested that we consider making an indanthrone dye-sensitized photocathode that would potentially add a few hundred more millivolts to his dye-sensitized water electrolysis system.

To perform that reduction, however, it would be necessary to develop a p-type thin film photocathode material. Dr. Lindquist from University of Uppsala suggested we look at nickel oxide. 
Some effort was expended investigating an effect reported by an IEA colleague where adding acetonitrile to water actually improved the rate of $\mathrm{H}_{2}$ evolution. We were unable to confirm that phenomenon, however.

Dr. Lindquist presented a paper where he was using Nafion as a separator membrane. When he complained about the cost, we offered to send him some polystyrene sulfonate sheets (Ionax MC-3470 and Neosepta CM-1), which promised to be much cheaper. We also resolved to send him some monosulfonated cobalt phthalocyanine to use as a dye sensitizer.

Overall, there was a push to consolidate our efforts around a central theme. It appeared that dye-sensitized solar cells could provide that focus. It was fine with us, since we had as much expertise as anybody there in organic pigment photochemistry. The other two US photoelectrolytic $\mathrm{H}_{2}$ groups, J. Turner's at National Renewable Energy Laboratory (not represented), and R. Rocheleau's at University of Hawaii (represented by Eric Miller) were probably not as enthused by the idea, as organic chromophores are not part of their research programs.

The second International Energy Agency Annex 14 meeting on Photoelectrolytic Production of Hydrogen that occurred during the contract period was held at Uppsala, Sweden, in September of 2001, with Dr. Lindquist as host. The meeting was fairly well attended, although missing personnel from Switzerland made it difficult to move forward on group planning. Our reports on dual bed photocatalytic water-splitting and dye sensitization of p-NiO were well received, although there were some comments that $\mathrm{NiO}$ is not a very good photocathode material. The terrorist attack on the US occurred during the Sweden trip, and so Dr. Linkous's return home was delayed by 2 days.

Also during the contract period, we learned that the next Annex 14 experts meeting on photoelectrolytic $\mathrm{H}_{2}$ of the International Energy Agency was to occur in Sapporo, Japan, in August of 2002. Since it lay outside the contract period, it was uncertain how to pay for the trip. A possible arrangement mentioned by N. Rossmeissl is that DOE might pay for the trip, if funds elsewhere are secured to support the dual bed work. As it turned out, funds were indeed secured from NASA to support the work. However, an additional requisite was that the other agency would have to write a letter to DOE requesting that we be allowed to participate in the annex activities using our contract funding. At this point, it is too early in the program for them to make a commitment of that nature.

It was decided that we would not participate in the IEA Annex 14 meeting set to occur before and after the $14^{\text {th }}$ International Conference on Photochemical Conversion and Storage of Solar Energy in early August of 2002. There was simply not enough time to work out an agreement between DOE and FSEC/UCF regarding the funding of the dual bed effort and participation in IEA. 


\section{Section 5. Energetics evalution}

We were contacted by Ed Skolnik of Energetics, Inc., with regard to having a site visit. This was part of a DOE contract where he was to visit a dozen or so contractors under the DOE Hydrogen Program, and prepare an evaluation on each.

Our visit took place on September $22^{\text {nd }}$ of 2000 . He had asked us for a portfolio of our reports and publications on the dual bed in advance of his visit, and then followed it with a list of questions to have answered. His questions and our answers are given in the following:

Questions/Discussion Topics for meeting with Dr. Clovis Linkous, FSEC, September 22, 2000.

1. Please discuss how you obtained an $8 \%$ solar to hydrogen efficiency estimate, and a \$13/MMBtu cost for hydrogen based on that efficiency.

This was done by making current and future (10 years) estimations of materials costs and combining them with realistic solar conversion efficiencies. The original work appeared in the proceedings of the $12^{\text {th }}$ World Hydrogen Energy Conference. I supplied a few of the numbers, but most of the work was done by Dave Block. A copy is attached.

Assumptions are:

Desert Southwest $\left(6.44 \mathrm{kWh} / \mathrm{m}^{2}\right)$

Glass paneling: $\$ 10 / \mathrm{m}^{2}$

Balance of system to collect $\mathrm{H}_{2}$ and $\mathrm{O}_{2}$ and to hold the cells at the correct latitude tilt angle: $\$ 120 / \mathrm{m}^{2}$. This value is the same as that which is commonly used for photovoltaic systems.

Capital cost is depreciated at 6\%/year over 20 years.

Operating cost/year is taken as $10 \%$ of the initial cost.

Photocatalyst cost: $\$ 50 / g$ (this gives us plenty of leeway for synthetic intricacy)

Photocatalyst loading: $5 \mathrm{mg} / \mathrm{cm}^{2}$ (actually some of our earlier work would suggest as low as $\left.2 \mathrm{mg} / \mathrm{cm}^{2}\right)$

Solar transmission losses (through glass covering and water layer): $11 \%$ and 5\%, respectively.

Fixed latitude tilt angle (modules not heliostated).

The conclusion is that if you can operate a dual bed system at $8 \%$ efficiency, the $\mathrm{H}_{2}$ could be sold at $\$ 13 /$ MBtu. There are literature citings where the conversion efficiency of semiconductor particulates for $\mathrm{H}_{2}$ evolution has been as high as $40 \%$, but that was done with the use of sacrificial electron donors. Our value is based on using water as the ultimate electron donor. In the next phase of the project, our task will be to sum the various optimized structural and material attributes of the system to show how the $8 \%$ value can be reasonably achieved. 
2. Has your previous work shown significant reverse reaction problems? Would you expect this phenomenon to be more or less of a problem with organic pigments?

We have run experiments where we stacked the deck toward the reverse reaction as much as possible (continuous $\mathrm{O}_{2}$-purging, high iodide concentration) in order to look at the worst possible case. Even then, we could not halt water-splitting; the rate of $\mathrm{O}_{2}$ consumption was only a small fraction of our measured rates of production. Furthermore, there is no reason to believe that the organics would promote the reverse reaction to any greater extent than the inorganics. If anything, it would be less.

3. Why do you believe that pigments will work better than semi conductors. What properties of pigments led you to consider them? For what reason did you abandon semiconductors?

In our view, the pigments are semiconductors. The properties of semiconductors are enabled by their segregated distribution of filled and empty electronic energy levels. Under these conditions, conductivity must be achieved by creating charge carriers (via injection, heating, or of course light absorption). This is in contrast to metallic conductors where a high density of charge carriers is always present. The arrangement of energy levels and the photoelectrochemical behavior of our pigments are consistent with the definition of semiconductors. While rigorously our pigments might be better classified as photoconductors, the same consideration would have to be applied to $\mathrm{TiO}_{2}$ and many other inorganic photoelectrode materials.

4. In your FY 2000 paper, you presented a plot for experimental vs. calculated ionization potential. You plan to use this as a correction mechanism to determine IP for a series of pigments by a simpler method, thereby screening the pigments. How accurate/reproducible is the plot? (For example, it appears that one data point lies halfway between the least squares line and a line that could be drawn for $y=x$, that is, for $I P(\exp )=I P($ calc $)$.

Within an analogous series of compounds, the correlation is quite good. An $\mathrm{R}^{2}$ value of 92\% was achieved in this case. The analogous series that we are most interested in consists of those organic pigments that have at least three fused rings and contain oxygen, nitrogen, or both. That may sound restrictive, but actually most of the compounds worth considering fit this description. If somebody suggests a pigment to us, we can run a 25 minute calculation on our p.c. and determine whether it will be good for water-splitting.

5. In the FY 2000 paper, you include in your oxygen evolution table, an entry for "acrylic blank". You indicate that this may represent background noise and must be subtracted out. Does this mean that only your top four pigments (Perylene Diimide through Perylene TCDA) outperform TiO2?

It turns out we were wrong about the acrylic blank. The acrylic blank value had nothing to do with the acrylic itself. We tested several other polymer substrates and got the same result. We ultimately discovered that the $\mathrm{O}_{2}$ was coming from a direct photolytic reaction between the deep UV part of the Xe lamp spectral distribution and the $\mathrm{IO}_{3}{ }^{-}$redox 
mediator. Inserting a UV filter in the beam eliminated the effect. It hurt us badly to present that result to the review panel. Now they are speculating that we can't even make $\mathrm{H}_{2}$ using visible wavelength light. They are plainly wrong, and we now have the data to prove it, but it's too late to have any impact on their harsh evaluation.

We have gone back and tested some, but not all, of the pigments. Certainly the four that we identified the first time through still outperform $\mathrm{TiO}_{2}$ and will provide plenty of work for us to do.

6. There appears to be an abundance of data for oxygen evolving pigments and only a small amount of data for hydrogen-evolving pigments. In addition, the amount of hydrogen formed appears to be less than 1/10 the amount of oxygen on a molar basis. Theoretically, we should be getting twice as much hydrogen as oxygen. Are the differences in the results simply due to different sized reactors, or is there an actual disparity? Are there plans to screen more pigments for hydrogen?

The UV effect described in the previous question accounts for the disparity. Actually, the rate constants for both reactions appear to be in the same ballpark. From a design and performance standpoint, it is desirable to have similar rate constants for both $\mathrm{O}_{2}$ and $\mathrm{H}_{2}$ evolution. This is especially true for future configurations of the dual bed design, since the photocatalytic layers will be stacked upon one another in a tandem arrangement.

Yes, we will be screening more pigments for $\mathrm{H}_{2}$. The reason we have emphasized $\mathrm{O}_{2}$ evolution over $\mathrm{H}_{2}$ evolution is that it is the more challenging problem. You need to be able to generate a rather large, positive potential to electrolytically evolve $\mathrm{O}_{2}$ from water. We determined that for any semiconductor substance to oxidatively split water, it should have an ionization potential of at least $7.5 \mathrm{eV}$. As it turned out, most pigments do not have a sufficiently large IP. To look at it another way, it is easy to find other organics that have a large enough IP, but they are poor absorbers of solar radiation. Relatively few of the endless array of organic compounds fulfill the conditions of large IP, visible wavelength absorption, and photochemical stability that we were looking for. Indeed, we deserve some credit for quickly coming up with a short list of pigments on our modest resources.

In contrast, there are a good many pigments whose electron affinity would indicate they are capable of water reduction to $\mathrm{H}_{2}$. Admittedly, we had spent comparatively little time looking at $\mathrm{H}_{2}$-evolvers going into the annual review meeting. We will certainly spend more time looking at $\mathrm{H}_{2}$ evolution in the next project period.

7. Your Annual Review presentation indicated that you planned to look at new membrane impregnation techniques. This task is not evident in your AOP write-up. Has it been abandoned? Do you feel that these techniques would not effect the degree of hydrogen formation?

The impregnation technique effort is hidden in the task 3a, "Module Constructionphotocatalyst and co-catalyst distribution." We are always looking for better ways of immobilizing the photocatalyst without reducing its activity. The same goes for the co- 
catalyst. The use of co-catalysts has been quite effective in improving gas evolution rates in both photocatalytic modules. Despite the need to work on better distribution techniques, we think one of great advantages of the dual bed approach in comparison to other photoelectrochemical methods is that when we finally develop an active system, it should be relatively easy to scale things up.

8. Your results for hydrogen evolution in your FY 2000 paper does not show a comparison to InP. What is the comparison?

We did not present data on InP because it is fundamentally unstable in the redox electrolyte that we are using. The initial rates of $\mathrm{H}_{2}$ evolution look impressive, but over the course of a few hours, gas evolution grinds to a halt. At first we thought it was just a photostationary state effect (equalization of forward and reverse reaction rates), but X-ray photoelectron analysis showed convincingly that the phosphide was being oxidized to the oxide ( $\mathrm{InP} \rightarrow \mathrm{In}_{2} \mathrm{O}_{3}$ ) and becoming inactive. Our first inclination was to call it photocorrosion, since many photoelectrodes are plagued with that problem, but ultimately we found that the alkaline iodate solution itself could decompose InP without even turning the light on.

9. You give results for oxygen and hydrogen evolution in units of volume. How large a system is used, and how long must it run to produce these volumes?

The samples were $3.0 \mathrm{~cm}$ in diameter, so that the total surface area was $7.1 \mathrm{~cm}^{2}$. The actual illuminated area was somewhat less; $6 \mathrm{~cm}^{2}$ is probably a good value. Photolysis time is 6 hours. The gas evolution rates from these sample were considerably less than when we use the same photocatalysts as free powders. The thing that really hurt us was the primitive way of admixing the co-catalyst powder. For the inorganic photocatalysts, we distribute the co-catalyst by performing a chemical reduction of a metal salt, a sort of electroless plating, but with the organics we had early on encountered some problems with this approach, and had gone away from it. In other photocatalytic research projects, we have been fairly successful at making photoactive formulations via direct admixture of powders, but for these experiments, it did not work out as well.

10. Please conceptualize a system where a dual bed photoelectrolytic system is providing hydrogen for, say, a vehicle refueling station. How large would the electrolytic system have to be? How often would you have to replace pigments, mediators, etc.?

Let's make the following assumptions:

Solar conversion efficiency: $8 \%$

Solar irradiance: $1.0 \mathrm{~kW} / \mathrm{m}^{2}$

Daily insolation: 6 hours at maximum solar irradiance $\left(6 \mathrm{kWh} / \mathrm{m}^{2}\right)$

Tandem cell (stacked) configuration

Station open from 7:00 AM to 9:00 PM

Steady flow of customers (no down time)

Single pumping station (we're not ready for self-serve)

Vehicle refilling time: 5 minutes

Capacity of vehicle fuel tank: four cylinders, 43.8 liters each, 2200 psi. 
As for lifetime performance or replacement costs, all we know at this point is that most of our pigments have shown no degradation after 6 hours.

$$
\begin{aligned}
& \mathrm{V}=\text { the volume output of } \mathrm{H}_{2} \text { at } 1.0 \text { atm and room temperature per unit area per } \\
& \text { day. } \\
& =(0.08)\left(1.0 \mathrm{~kW} / \mathrm{m}^{2}\right)\left(10^{3} \mathrm{~W} / \mathrm{kW}\right)(1 \mathrm{~J} / \mathrm{W}-\mathrm{s})(1 \mathrm{cal} / 4.184 \mathrm{~J})\left(10^{-3} \mathrm{kcal} / \mathrm{cal}\right) \\
& \text { (1mol/56.6 kcal)(24.5 L/mol)(3600 s/hr)(6 hr/day) } \\
& =178 \mathrm{~L} \mathrm{H}_{2} / \mathrm{m}^{2} \text {-day } \\
& \mathrm{C}=\text { fuel capacity of each vehicle at same pressure and temperature as stated } \\
& \text { above } \\
& =(4 \text { tanks })(43.8 \mathrm{~L} / \operatorname{tank})(2200 / 14.7) \\
& =26,220 \mathrm{~L} \text { (about enough to cruise at highway speeds for } 2 \text { hours) } \\
& A=\text { area required to supply the entire daily station demand for fuel } \mathrm{H}_{2} \text {. } \\
& =\frac{(14 \mathrm{hr} / \mathrm{day})(12 \mathrm{cars} / \mathrm{hr}) \times \mathrm{C}}{\mathrm{V}} \\
& =24,746 \mathrm{~m}^{2}, \text { or } \sim 6 \text { acres }
\end{aligned}
$$

That's a lot of real estate, but the numbers have little to do with the dual bed technology itself. Rather, it's a reflection of the intensity of sunlight versus the energy consumption of an automobile.

Some time after Mr. Skolnik's visit, we contacted him to obtain a couple of his report on the visit. He maintained that the report was not completed yet, and that the report had no effect on future funding. He maintained this position right up to and through the annual contractors review meeting in May of the following year. Yet, based on the questions posed by the reviewers, it was obvious they had read something related to Skolnik's evaluation of the dual bed project.

Finally, some thirteen months after being visited, we obtained Skolnik's report on our work. The report was generally upbeat, but pointed out that we must achieve a threeorder-of-magnitude improvement in quantum efficiency to be economically viable. We prepared a response to DOE, indicating that we are continuing our systems studies, and will be looking at dye sensitization schemes, where our pigments are employed as thin layers on inorganic semiconductors. 
Appendix A 


\title{
Appendix A: Dyes and Pigments Paper
}

\section{Semiempirical MO and Voltammetric Estimation of Ionization Potentials of Organic Pigments. Comparison to Gas Phase Ultraviolet Photoelectron Spectroscopy}

\author{
Darlene K. Slattery ${ }^{\mathrm{a},{ }^{,}}$, Clovis A. Linkous ${ }^{\mathrm{a}}$, Nadine E. Gruhn ${ }^{\mathrm{b}}$ and J. Clayton Baum ${ }^{\mathrm{c}}$ \\ ${ }^{a}$ Florida Solar Energy Center, 1679 Clearlake Road, Cocoa, FL 32922 \\ ${ }^{\mathrm{b}}$ Dept. of Chemistry, The University of Arizona, Tucson, AZ 85721 \\ ${ }^{\mathrm{c}}$ Dept. of Chemistry, Florida Institute of Technology, Melbourne, FL 32901
}

\begin{abstract}
A number of organic pigments were identified by semiempirical molecular orbital calculations, using the PM3 method, as having ionization potential (IP) values of 7.0 $9.5 \mathrm{eV}$. Based on photostability, solubility and commercial availability twelve (quinacridone, isoviolanthrone, indanthrone indigo, 3,4,9,10 perylenetetracarboxylic dianhydride, bis(p-chlorophenyl)1,4-diketopyrrolo (3,4-C) pyrrole, pyranthrone, indanthrene yellow GCN, 16, 17-dimethoxyviolanthrone, indanthrene gold orange, 4,4' diamino-9,9', 10,10'-tetrone [1,1' bianthracene], and N,N' ditridecyl-3,4,9,10perlenetetracarboxylic diimide) were chosen for further experimental study. The accuracy of the MO calculations was confirmed by experimental measurement of the ionization potentials for eight of the pigments using gas phase ultraviolet photoelectron spectroscopy. For compounds having at least three fused rings and containing oxygen, nitrogen, or both, the theoretical and experimental IPs have a linear relationship defined by the equation $\mathrm{IP}_{\exp }=0.694 \mathrm{IP}_{\text {Calc }}+1.9049$. Lewis acid pigment solubilization (LAPS) was shown to be a viable approach to preparing electrodes for cyclic voltammetry of pigment solid films. The results of the cyclic voltammetry were utilized to formulate the equation $\mathrm{E}_{\mathrm{ox}}(\mathrm{V}$ vs. $\mathrm{NHE})=0.5488 \mathrm{IP}_{\text {Calc }}-3.042$, which relates the experimental oxidation potential to the theoretical IP.
\end{abstract}

Keywords: Pigments; ionization potentials; redox potentials; molecular orbital calculations; cyclic voltammetry; UPS

\section{Introduction}

There are many reasons for the present interest in the ionization potentials (IPs) of compounds, including the use of such values to select appropriate materials for xerography, photography, or electroluminescence applications [i,ii]. IP values are especially valuable when examining organic semiconductors for specific uses, since the IP and electron affinity (EA) correspond to the valence and conduction band edges of the material, respectively. While the literature contains an abundance of IP data for organic compounds [iii], little experimental data is available on the energy levels of large organic pigments.

\footnotetext{
“ Corresponding author. Fax: 321-638-1010. E-mail address: dkslatt@fsec.ucf.edu
} 
Pigments are primarily of interest in the coatings and plastics industries. For such applications, characteristics such as tinctorial strength, lightfastness and weatherability are more significant than IP or EA values. However, our interests involved making use of the insolubility and lightfastness of pigments for photoelectrochemical studies that also required a knowledge of the energy of the highest occupied molecular orbital (HOMO). IP and EA data can be used to develop an efficient, affordable, direct photoconversion scheme for generating $\mathrm{H}_{2}$ and $\mathrm{O}_{2}$ from $\mathrm{H}_{2} \mathrm{O}$ using sunlight [iv].

The preferred method for the direct measurement of gas phase IPs is by ultraviolet photoelectron spectroscopy. IPs are also related by Koopmans' Theorem to the eigenvalues of the one-electron molecular orbitals obtained from theoretical calculations [v]. In addition, there are numerous commercial PC-based quantum chemistry software packages that employ semi-empirical MO methods to quickly and affordably calculate the energies of the HOMO and lowest unoccupied molecular orbital (LUMO) for molecules the size of a typical organic pigment.

With this is mind, our intent, in the present work was to calculate HOMO energies for a series of related organic pigments and to assess the reliability of the calculated values by comparing them to experimental IPs and oxidation potentials determined via cyclic voltammetry. Calculations were performed using the widely available PM3 semiempirical Hartree-Fock method as implemented in the CAChe desktop software package.

\section{Experimental}

\subsection{MO Calculations}

Calculation of the HOMO and LUMO for each pigment was accomplished using CAChe $^{\circledR} 3.0$ software from Oxford Molecular Group, running on a $233 \mathrm{MHz}$ Pentium II computer. The molecular structures were drawn within the input module of the program and the valence, hybridization, and initial geometry of each structure were corrected using the "beautify" option. After a preliminary geometry optimization by molecular mechanics (MM2) additional optimization was performed using PM3 parameters. The fully optimized structures were then submitted for PM3 calculation of the wavefunctions, including the HOMO and LUMO.

\subsection{Ultraviolet Photoelectron Spectroscopy}

The gas phase ultraviolet photoelectron spectra were recorded using an instrument and procedures that have previously been described in detail [vi]. The argon ${ }^{2} \mathrm{P}_{3 / 2}$ ionization at $15.759 \mathrm{eV}$ was used as an internal calibration lock of the absolute ionization energy, and the difference between the argon ${ }^{2} \mathrm{P}_{3 / 2}$ ionization and the methyl iodide ${ }^{2} \mathrm{E}_{1 / 2}$ ionization at $9.538 \mathrm{eV}$ was used to calibrate the ionization energy scale. During data collection the instrument resolution (measured using FWHM of the argon ${ }^{2} \mathrm{P}_{3 / 2}$ peak) was 0.015-0.030 eV. Ionization peak positions were reproducible to $\pm 0.02 \mathrm{eV}$. 


\subsection{Pigment Solubilization}

Solutions were prepared under an inert atmosphere in a glovebox. Using a process developed by Hsieh and Melnyk [vii], $6 \mathrm{~mL}$ of nitromethane and $4 \mathrm{~mL}$ of methylene chloride were combined and $0.33 \mathrm{~g}$ of aluminum chloride was added. After stirring to dissolve the $\mathrm{AlCl}_{3}, 0.4 \mathrm{mmol}$ of the pigment were added. The flasks were stoppered and the solutions were allowed to stir for 6-18 hours.

\subsection{Electrode Preparation}

The working electrode was a $1.0 \mathrm{~cm}^{2}$ platinum foil. The electrode was passed through a hydrogen flame and then, under an inert atmosphere, was dipped in the pigment/nitromethane solution 1-7 times to form a visible coating, allowing time to dry between coats. After coating, the electrode was removed from the glove box and dipped in deionized water to remove any residual solvent mixture. It was then placed in a warm oven at approximately $110{ }^{\circ} \mathrm{C}$ until dry.

\subsection{Voltammetry}

Voltammetric experiments were conducted using an EG\&G Princeton Applied Research Potentiostat/Galvanostat model 273A, with data collected using a Hewlett Packard 7015B chart recorder. A three-electrode, single compartment configuration was used, with a platinum mesh counter electrode, and a $\mathrm{Ag} / \mathrm{AgClO}_{4}$ reference electrode. To convert the potentials to the more common normal hydrogen electrode (NHE) values, voltammograms were recorded for a ferrocene solution, first using a commercial saturated calomel electrode, SCE, and then the $\mathrm{Ag} / \mathrm{AgClO}_{4}$ electrode as the reference electrode. The $\mathrm{Ag} / \mathrm{AgClO}_{4}$ electrode was found to have a potential of $+0.043 \mathrm{~V}$ when compared to the SCE. Therefore, $0.285 \mathrm{~V}$ was added to the potentials obtained using the $\mathrm{Ag} / \mathrm{AgClO}_{4}$, in order to reflect values obtained with an NHE.

\section{Each scan was initiated at $0 \mathrm{~V}$ and the scan rate was $150 \mathrm{mV} / \mathrm{s}$. Because the electrode coating eroded with prolonged cycling, the initial cycle was recorded rather than a steady state cycle. If this initial scan showed irregularities, a new electrode was prepared and the experiment was repeated.}

The voltammetry was performed in a mixture of $0.1 \mathrm{M}$ tetraethylammonium perchlorate and DMSO when investigating reduction potentials, and $0.1 \mathrm{M} \mathrm{LiClO}_{4}$ in acetonitrile was used as the medium for oxidation potential studies. The solvents (anhydrous) were obtained from Aldrich Chemicals and were used as received.

\section{Results and Discussion}

The relationship between the oxidation-reduction, or redox, potentials and the ionization potentials-electron affinities (IP-EA) of molecules has long been recognized. Maccoll 
[viii] first related redox potentials to the HOMO and LUMO energies of a molecule, and other researchers, including Dewar [ix], have related redox potentials to IP-EA.

In order to select an initial group of pigments with which to conduct further studies, we performed MO calculations on a large number of pigments, looking for representatives having a calculated HOMO of 7.0 - $9.5 \mathrm{eV}$. The list of pigments was then narrowed to 12 candidates based on photostability, insolubility and commercial availability. Structures for the resultant pigments are shown in Table I.

To confirm the accuracy of the MO calculations, eight of the pigments were analyzed by gas phase ultraviolet photoelectron spectroscopy. A comparison of calculated and experimental IP values is given in Table II. Having previously conducted PM3 calculations on a number of compounds for which there were published IP values [x], it was anticipated that the experimental IP values would reflect higher HOMO energies than the calculated values. This hypothesis was confirmed, and similar results were obtained using the AM1 semiempirical method. The AM1 method typically gave HOMO energies that are $\approx 1 \mathrm{eV}$ lower than experimental values from gas phase IPs [xi,xii]. The experimental first ionization energies of the tested compounds varied from $6.78 \mathrm{eV}$ for indanthrone to $8.22 \mathrm{eV}$ for perylenetetracarboxylic dianhydride. The photoelectron spectrum of dimethoxyviolanthrone, rather than have well separated ionization bands, had a continuum of ionizations of $7.6-11 \mathrm{eV}$, as shown in Figure 1.

For a few of the pigments studied, the calculated HOMO energies were significantly lower than the experimental values. The deviation between calculated and experimental ionization potential was most pronounced for DPP and indigo. This may due to their structural dissimilarity in comparison to the mostly fused ring structures comprising the other pigments. Indigo and DPP are the only compounds studied with five-membered rings, so that their parameter sets may not have adequately considered intermolecular $\pi-\pi$ interactions. The presence of halogen atoms on DPP and indanthrene gold orange may also have caused greater than normal deviations.

To aid in the correlation of calculated and experimental IP values for future calculations involving similar compounds, a calibration curve for the theoretical versus experimental IPs was constructed. The resultant plot had a correlation coefficient of 0.8587 . When the values for indigo and DPP were excluded from the calibration curve, Eq. (1) was derived, and the correlation coefficient improved to 0.9227 .

$$
\mathrm{IP}_{\mathrm{exp}}=0.694 \mathrm{IP}_{\text {Calc }}+1.9049
$$

As additional corroboration of the MO calculations and to define the relationships between the gas phase and solid phase energy levels, experimental redox potentials were determined and are also listed in Table II. While voltammetry is more frequently conducted with the electroactive species dissolved in water or an organic solvent, solid state or thin film voltammetry is becoming more widely used [xiii,xiv,xv,xvi]. In the present research, redox potentials were determined in the solid state because of low 
pigment solubility and because the intended end use of these pigments involved the solid state.

Hsieh and Melnyk developed Lewis acid pigment solubilization, LAPS, [ vii] for the fabrication of multilayered organic photoconductors. Initially, we had planned to use pigment solutions to conduct solution voltammetry; however, difficulties were encountered as a result of the nitromethane used in the solubilization technique. In the presence of $\mathrm{AlCl}_{3}$, nitromethane, forms the electroactive nitrosyl cation, complicating the electrochemistry [xvii,xviii]. Although it was not possible to use the pigment/nitromethane solutions to do electrochemistry, these solutions were useful for coating electrodes for thin film voltammetry.

The reductions were easily obtained although, in many cases, the wave exhibited a shoulder that was due to the adsorbed and solution phases of the pigments [xix]. It was especially interesting to note that while the parent pigments were virtually insoluble in the DMSO, the reduced forms were more soluble in this solvent. During the potential sweep, the pigment being studied slowly dissolved from the electrode. Frequently, the solvent directly around the electrode (and sometimes the electrode coating) developed a color different from that of the original pigment, as observed with the reduction of vat dyes. For instance, during the voltammetry with the dark blue pigment isoviolanthrone, the solution surrounding the electrode became rose-colored. A sample of isoviolanthrone added to fresh DMSO was not soluble and no color appeared in solution, providing evidence that only the reduced form was soluble.

The voltammetry experiments that were conducted to determine the oxidation potentials were more difficult than the reductions. Several compounds gave quasi-reversible voltammograms in which the peaks were of equal size but whose separation was far greater than the $59 \mathrm{mV}$ expected for a reversible oxidation. A representative voltammogram can be seen in Figure 2 for dimethoxyviolanthrone. Others, on reversal, had cathodic waves that were either absent or very small (see Figure 3), an indication that the cation radical undergoes a rapid chemical reaction after electron transfer [xx] or that the charge transfer rate is slow. Unlike the solubility behavior observed following reductions, the oxidized species were insoluble. The peak potentials for the irreversible oxidations were corrected by subtracting $0.15 \mathrm{~V}$, to give an approximation of the oxidation potential [xxi].

The difficulties encountered in obtaining oxidation potentials emphasized the advantages of having a method for obtaining the desired data, even when the resultant cation is unstable. It is reasonable, therefore, to investigate the relationship between calculated IPs and experimental oxidation potentials, as a way to approximate the oxidation potential. A number of researchers [,xxii,xxiii] have discussed the rationale for equating the two values and have shown that a useful relationship exists. The equations developed, however, are valid only for structurally similar compounds, because the constants in the equations take into account differences in the solvation energies of the oxidized species and the parent molecule, as well as the potential of the reference electrode. Changes in geometry that could occur when an electron is removed during the slow time scale of a voltammetry experiment can also cause experimental oxidation potentials to differ from 
the calculated, frozen geometry HOMO energies. An analysis of the calculated IP and experimental $\mathrm{E}_{\mathrm{ox}}$ data obtained in our study gave equation (2), which can only be used for determining oxidation potentials for closely related compounds in the solid state.

$$
\mathrm{E}_{\text {ox }}(\mathrm{V} \text { vs. NHE })=0.5488 \mathrm{IP}-3.042 \quad \mathrm{R}^{2}=0.7285
$$

The dissimilar compounds, indigo and DPP, again were excluded from the calibration curve, as was indanthrene yellow, the only sulfur containing compound. Including these compounds dramatically decreased the correlation coefficient to 0.2890 . The complete listing of redox potentials, theoretical ionization potentials and experimental ionization potentials are shown in Table II.

\section{Conclusion}

In this work, we have developed equations that correlate the results of MO calculations to the experimentally determined ionization and oxidation potentials of organic pigments that have at least three fused rings and contain oxygen, nitrogen, or both. These equations may be used to estimate the IP or oxidation potential of additional pigments having similar molecular structures. Furthermore, we have demonstrated that LAPS can be used as a technique to prepare thin film electrodes for cyclic voltammetry.

\section{Acknowledgements}

Two of the authors, DKS and CAL, would like to thank Prof. Harold Freeman at North Carolina State University, for his advice and guidance early in the project. We also thank Ciba-Geigy for the donation of a number of the pigments, and the Department of Energy, Office of Solar Thermal, Biomass Power, and Hydrogen Technologies for financial support. Gas phase UPS were collected at the Center for Gas phase Electron Spectroscopy, Department of Chemistry, The University of Arizona. 


\section{References}

[1] Zhang X, Shetty AS, Jenekhe SA. Macromolecules 1999; 32: 7422-7429.

[2] Liu S-F, Wu Q, Schmider HL, Aziz H, Hu N-X, Popovic Z, Wang S. J Am Chem Soc 2000; 122: 3671-3678.

[3] For example, compilation of experimental IPs of organic molecules can be found in: Kimura K, Katsumata S, Achiba Y, Yamazaki T, Iwata S. Handbook of HeI Photoelectron Spectra of Fundamental Organic Molecules. Tokyo: Japan Scientific Societies Press, 1981; Heilbronner E, Maier JP. In Brundle CR, Baker AD, Editors. Electron Spectroscopy: Theory, Techniques and Applications, Vol. I. New York: Academic Press, 1977. p. 205-293; Turner DW, Baker C, Baker AD, Brundle CR. Molecular Photoelectron Spectroscopy. New York: WileyInterscience, 1970.

[4] Slattery DK, Linkous CA, Gruhn NE. Polymer Preprints 2000; 41: 866-867.

[5] Salem L. Molecular Orbital Theory of Conjugated Systems. Reading, Massachusetts: W.A. Benjamin, 1974 p 155.

[6] Westcott BL, Gruhn NE, Enemark JH. J Am Chem Soc 1998; 120: 3382-3386.

[7] Hsieh BR, Melnyk AR. Chem Mater 1998; 10: 2313-2316.

[8] MacColl A. Nature 1949; 163: 138-139.

[9] Dewar MJS, Hashmall JA, Trinajstic NJ. Am Chem Soc 1970; 92: 5555-5559.

[10] Slattery DK. Ph.D. Dissertation, Florida Institute of Technology, 1999.

[11] Cornil J, Vanderdonckt S, Lazzaroni R, dos Santos DA, Thys G, Geise HJ, Yu LM, Szablewski M, Bloor D, Logdlund M, Salaneck WR, Gruhn NE, Lichtenberger DL, Lee PA, Armstrong NR, Bredas JL. Chem Mater 1999; 11: 2436-2443. 
[12] Cornil J, Gruhn NE, dos Santos DA, Malagoli M, Lee PA, Barlow S, Thayumanavan S, Marder SR, Armstrong NR, Brédas JL. J Phys Chem A, submitted.

[13] Stern DA, Wellner E, Salaita GN, Laguren-Davidson L, Lu F, Hubbard AT. J Am Chem Soc 1988; 110: 4885-4893.

[14] Janietz S, Bradley DDC, Grell M, Giebeler C, Inbasekaran M, Woo EP. Applied Phys Lett 1998; 73: 2453-2455.

[15] Anderson JL, Coury Jr LA, Leddy J. Anal Chem 1998; 70: 519R-589R.

[16] Yang C, He G, Wang R, Li Y. J Electroanal Chem 1999; 471: 32-36.

[17] Bauer D, Foucault A. J Electroanal Chem and Interfacial Electrochem 1972; 39:385-394.

[18] Paul RC, Kaushal R, Pahil SS. J Indian Chem Soc 1967; 44: 920-926.

[19] Bard AJ, Faulkner LR. Electrochemical Methods, Fundamentals and Applications. New York: Wiley \& Sons, Inc, 1980. p. 519-534.

[20] Phelps J, Santhanam KSV, Bard AJ. J Am Chem Soc 1967; 89: 1752-1753.

[21] Miller LL, Nordblom GD, Mayeda EA. J Org Chem 1972; 6: 916-918.

[22] Loutfy RO, Sharp JH. Photographic Science and Engineering 1976; 20(4): $165-174$.

[23] Tang TB, Yamamoto H, Imaeda K, Inokuchi H, Seki K, Okazaki M, Tani T. J Phys Chem 1989; 93: 3970-3973. 
Table I. Pigments used in this study.

Table II. Ionization and Redox Potentials for pigments used in this study.

Figure 1. Ultraviolet Photoelectron Spectrum of Dimethoxyviolanthrone

Figure 2. Cyclic Voltammogram for the Oxidation of Dimethoxyviolanthrone

Figure 3. Cyclic Voltammogram for the Oxidation of bis (p-chlorophenyl) DPP 


\section{Table I. Pigments and Structures}

\begin{tabular}{|c|c|}
\hline & STRUCTURE \\
\hline \multicolumn{2}{|c|}{ Quinacridone } \\
\hline \multicolumn{2}{|c|}{ Isoviolanthrone } \\
\hline \multicolumn{2}{|l|}{ Indanthrone } \\
\hline \multicolumn{2}{|l|}{ Indigo } \\
\hline \multicolumn{2}{|c|}{ 3,4,9,10-Perylenetetracarboxylic dianhydride } \\
\hline \multicolumn{2}{|c|}{ Bis(p-chlorophenyl) 1,4-diketopyrrolo (3,4-C) } \\
\hline \multicolumn{2}{|c|}{ pyrrole (DPP) } \\
\hline \multicolumn{2}{|l|}{ Pyranthrone } \\
\hline
\end{tabular}


Indanthrene Yellow GCN

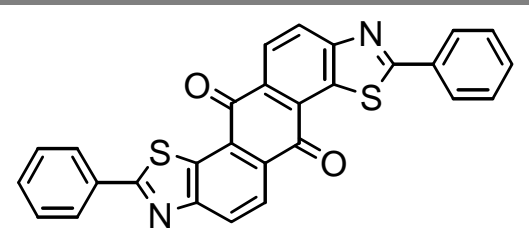

16,17-Dimethoxyviolanthrone

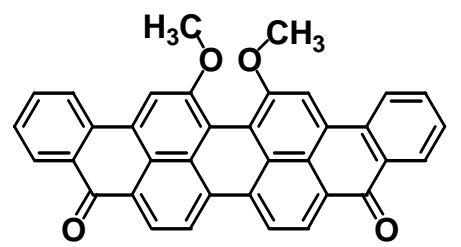

Indanthrene Gold Orange

4,4'-diamino-9, 9', 10, 10'-tetrone [1,1' Bianthracene] (Pigment Red 177)<smiles>O=C1C(=O)c2ccc3c4c(ccc(c24)-c2cc(Br)ccc21)C(=O)c1cc(Br)ccc1-3</smiles><smiles>Nc1ccc(-c2ccc(N)c3c2C(=O)c2ccccc2C3=O)c2c1C(=O)c1ccccc1C2=O</smiles>

N,N' Ditridecyl-3,4,9,10-

Perylenetetracarboxylic Diimide (Perylene Diimide)

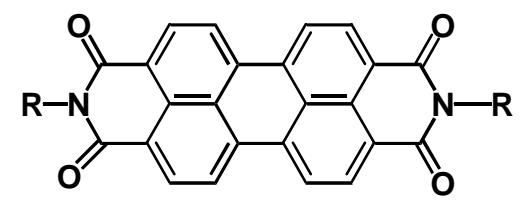


Table II. Ionization and Redox Potentials

\begin{tabular}{|c|c|c|c|c|}
\hline Pigment & $\mathbf{I P}_{\text {calc }}$ & $\mathbf{I P}_{\exp }$ & $E_{\text {red }}$ (vs NHE) & $\mathrm{E}_{\mathrm{ox}}$ (vs NHE) \\
\hline Quinacridone & 7.65 & 7.23 & -1.11 & 1.39 \\
\hline Isoviolanthrone & 8.22 & 7.87 & -0.34 & 1.54 \\
\hline Indanthrone & 7.25 & 6.78 & -0.29 & 0.99 \\
\hline Indigo & 8.34 & 7.23 & -0.37 & 1.19 \\
\hline Perylenetetracarboxylic & 9.31 & 8.22 & -0.05 & 2.29 \\
\hline \multicolumn{5}{|l|}{ dianhydride } \\
\hline DPP & 8.50 & 7.47 & -0.70 & 1.49 \\
\hline Pyranthrone & 8.54 & NA & -0.30 & 1.39 \\
\hline Indanthrene Yellow & 9.41 & NA & NA & 1.09 \\
\hline Dimethoxyviolanthrone & 7.90 & $>7.60$ & -0.34 & 1.16 \\
\hline Indanthrene Gold Orange & 8.84 & 8.07 & -0.03 & 1.50 \\
\hline Pigment Red 177 & 8.21 & NA & -0.56 & 1.32 \\
\hline Perylene Diimide & 8.87 & NA & -0.14 & 2.09 \\
\hline
\end{tabular}


Figure 1.

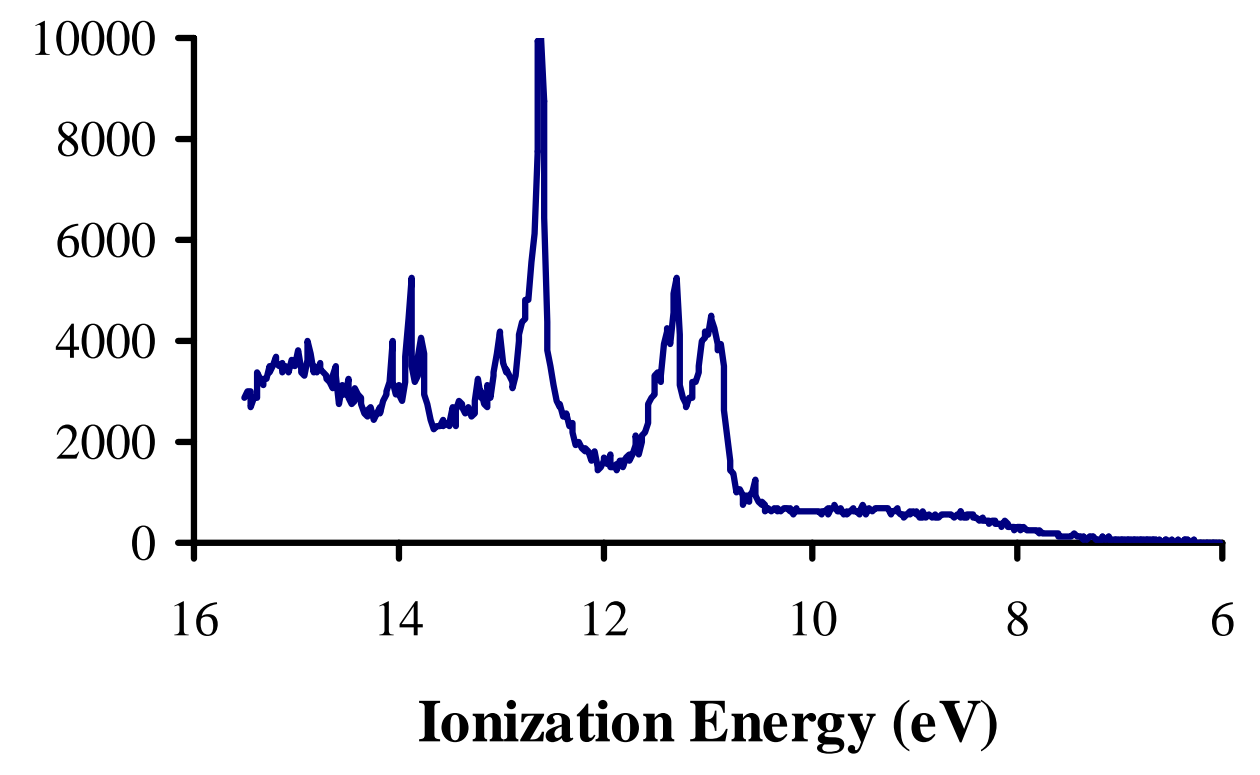


Figure 2.

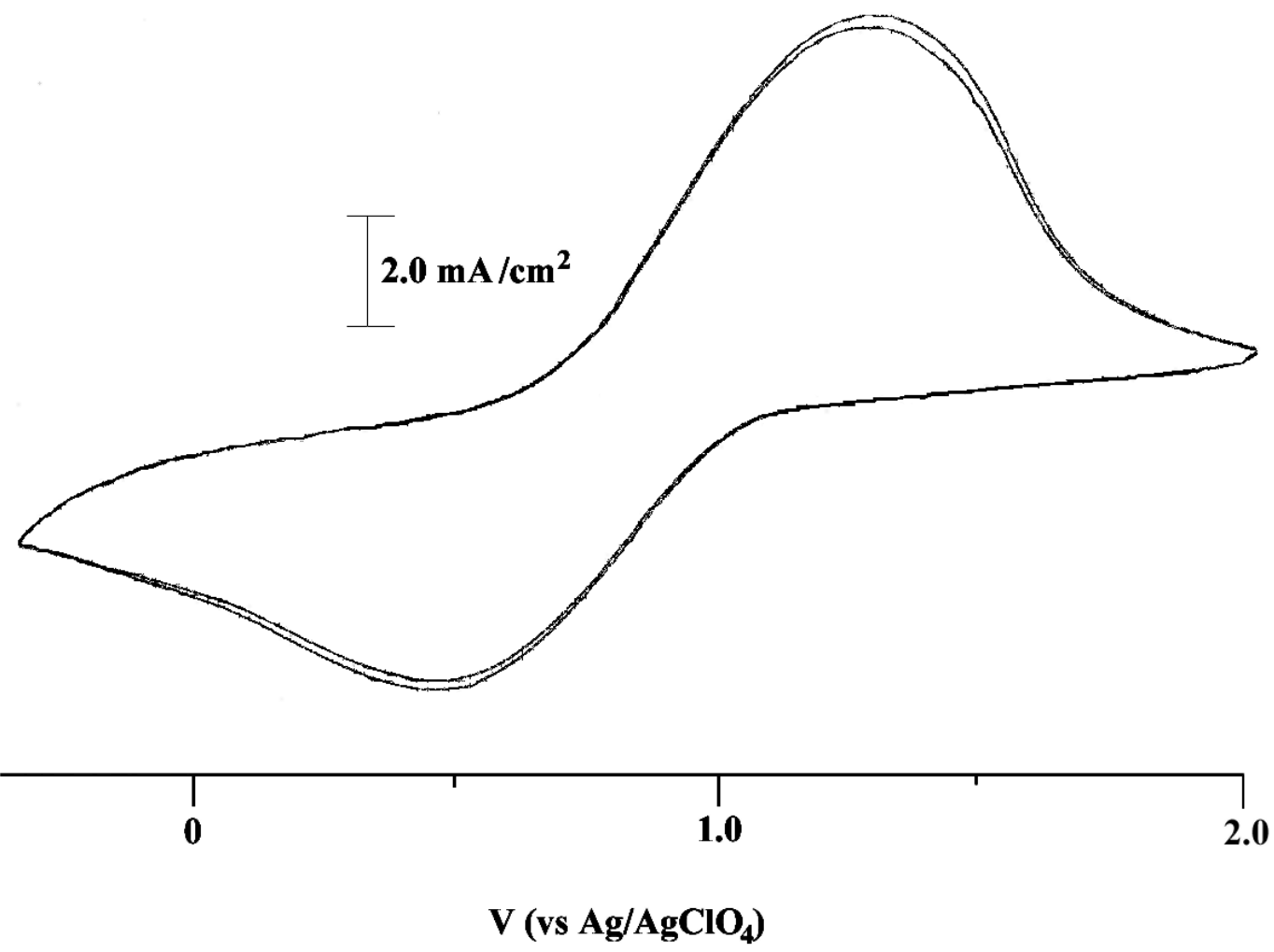


Figure 3.

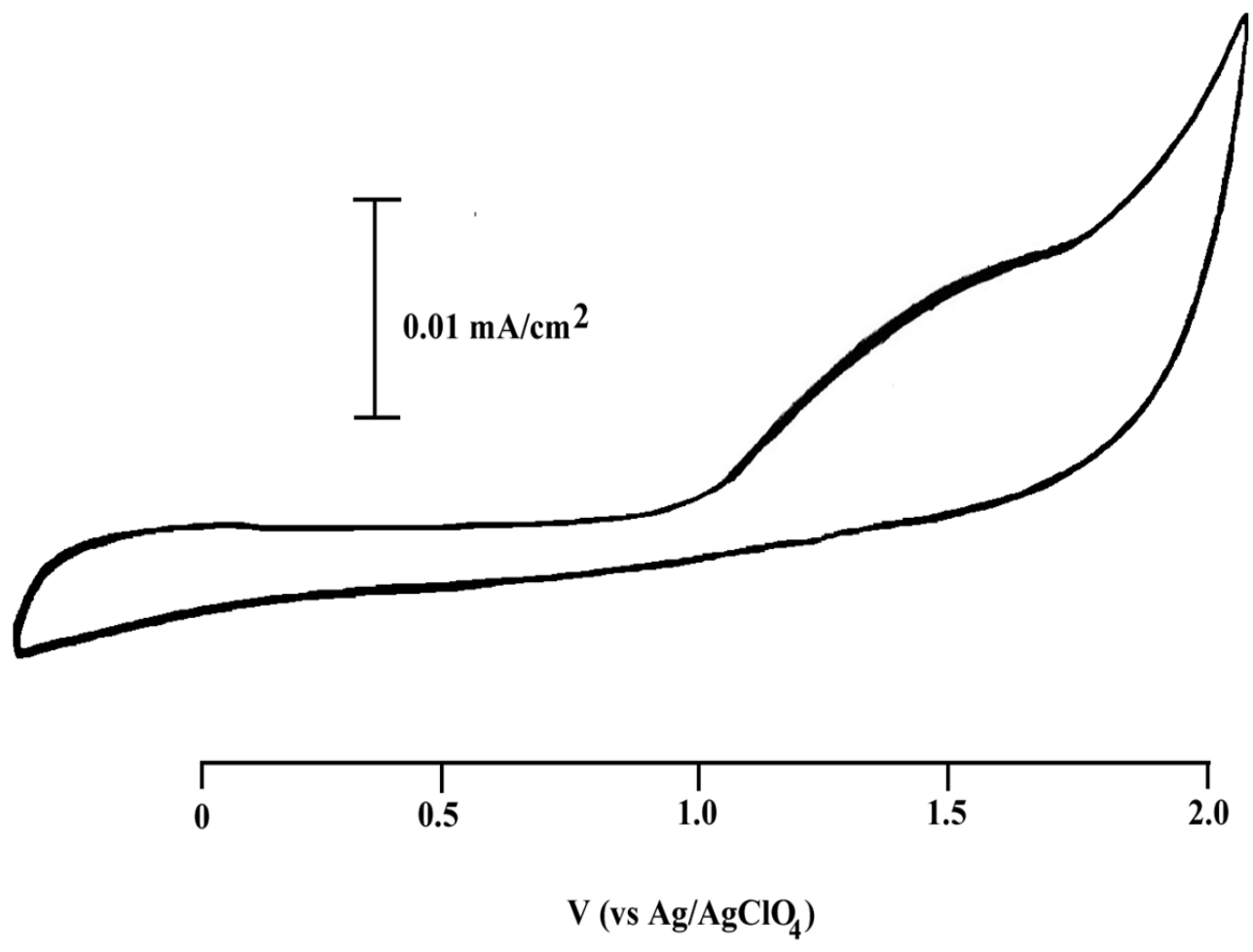


Appendix B 


\title{
Appendix B. proceedings paper from World Hydrogen Energy Conference XIV
}

\section{COUPLING OF ORGANIC PIGMENT PHOTOCATALYTIC SYSTEMS TO PRODUCE HYDROGEN FROM WATER}

\author{
C. A. Linkous, D. K. Slattery, and J. R. Fowler ${ }^{1}$
}

We are developing a dual stage photocatalytic approach to solar water decomposition, where $\mathrm{H}_{2}$ and $\mathrm{O}_{2}$ are evolved from separate modules while a redox electrolyte flows between them. Organic pigments were immobilized along with noble metal co-catalysts on acrylic flats and tested for gas evolution. Selective gas evolution using visible wavelength light was observed for a number of materials. Testing mediators of varying reversibility in an electrochemical system equivalent demonstrated that to ensure cyclical operation, provision must be made for inhibiting the photocatalytic back reaction.

\section{Introduction}

One of the fundamental problems in solar-to-hydrogen energy conversion is how to utilize the photon energies associated with the visible part of the solar spectrum to generate enough chemical potential to drive water decomposition. One approach that is found in systems varying from tandem photovoltaic cells to natural photosynthesis is to couple two or more photosystems together so that the electronic energy stored upon photon absorption by each respective system is additive to the others. [1-6] That way, abundant low energy photons can add their energies together to enable water-splitting. This is accomplished through careful selection of photoactive materials according to the positions of their ground and excited state electronic energy levels. Semiconducting compounds whose band gap energies correspond to the photon energies inherent in visible wavelength light are commonly used for this purpose.

We are employing semiconductors in particulate form in a dual stage, or dual bed, photocatalytic process to accomplish water-splitting. A schematic of the dual bed concept is shown below in Figure 1. Two pairs of photocatalytic reactions occur. In one container, water is reduced to $\mathrm{H}_{2}$; the electron equivalents for the reaction come from a redox mediator, $\mathrm{M}$. In the second container, water is oxidized to evolve $\mathrm{O}_{2}$; here the oxidized form of the mediator acts as electron acceptor. By circulating the mediator in an aqueous solution between the beds, the transfer of charge equivalents between the two water decomposition half-cell reactions is accomplished. While the maximum quantum efficiency for water-splitting is automatically cut in half, one is now able to utilize lower energy photons to perform less energetically demanding chemical steps, and so achieve better utilization of the solar spectrum.

\footnotetext{
${ }^{1}$ Florida Solar Energy Center, University of Central Florida
} 
Our early work in this area involved the use of inorganic semiconductors and metal oxides. Difficulties encountered included those found in semiconductor photoelectrochemistry when applied to solar energy conversion, namely, narrow band gap semiconductors making efficient use of the solar spectrum were subject to corrosion, and wide band gap materials such as $\mathrm{TiO}_{2}$ were found to be stable, but could only absorb the ultraviolet portion of incident sunlight. [1,4] Subsequently, we identified a number of organic pigments whose energy levels are complementary to each other and may be employed in a photocatalytic water-splitting scheme. [7,8] For $\mathrm{H}_{2}$ evolution, it was determined that pigments such as quinacridone and Indanthrene Yellow would have a conduction band edge or excited state energy level sufficiently negative on the redox potential scale to reduce water and generate $\mathrm{H}_{2}$. For $\mathrm{O}_{2}$ evolution, perylene dianhydrides and diimides, indanthrone, and others were determined to have a valence band or filled energy level that would be able to oxidize water and generate $\mathrm{O}_{2}$.

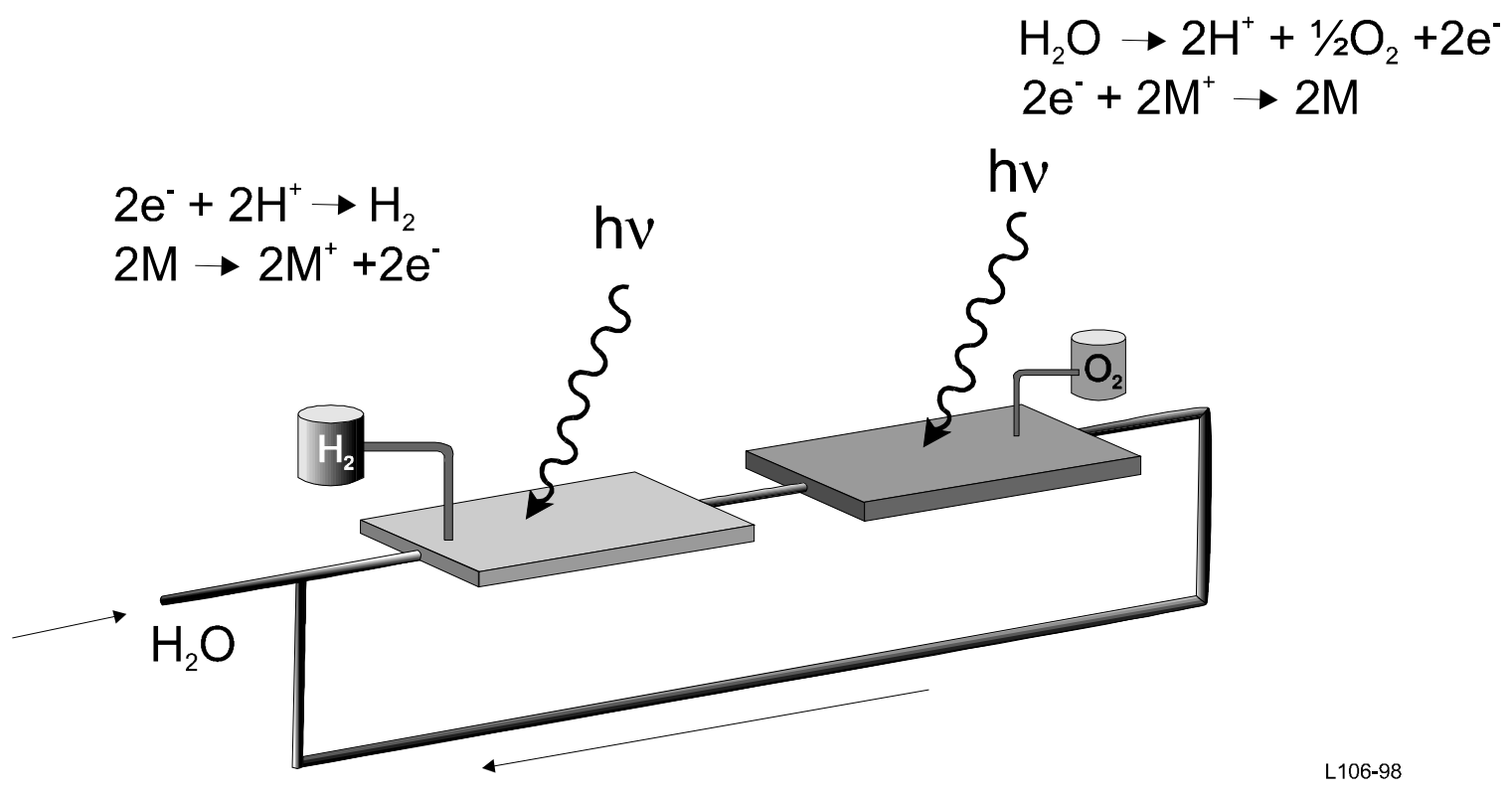

Figure 1. Schematic of a Dual Bed Photocatalytic Water-Splitting System.

Our research efforts have gone along two basic directions: 1) photocatalyst development; and 2) systems development. In this report, results are given for gas evolution experiments utilizing the various pigments as photocatalysts for $\mathrm{H}_{2}$ and $\mathrm{O}_{2}$ evolution. On the systems level, it was of interest to study the dynamics of interconversion of the redox electrolyte between the oxidized (Ox) and reduced (Red) forms of the electron transfer agent in the circulating electrolyte. In order for the dual bed system to work properly, there must be a substantial conversion of Red to $\mathrm{Ox}$ in the $\mathrm{H}_{2}$ vessel and vice versa in the $\mathrm{O}_{2}$ vessel. At the very least, one must establish an identical $\mathrm{Ox} / \mathrm{Red}$ ratio where each module can perform its respectively gas evolution reaction and shift the ratio in opposite direction from the initial value. The organic pigment systems are not yet active enough to facilitate quantitative conversion of the mediator, which is typically present in $0.1 \mathrm{M}$ concentration. Therefore, we opted to construct an electrochemical circuit array with which the necessary photopotential equivalents could be externally applied. 


\section{Experimental}

All pigments in this work were acquired from commercial vendors. Ditridecylperylenetetracarboxylic diimide was obtained from Aldrich. Quinacridone and indanthrone were obtained from Ciba-Geigy. Copper, nickel, and vanadyl phthalocyanines had been previously obtained from Eastman Organic Chemicals. The electron transfer agents potassium iodide/iodate $\left(\mathrm{I}^{-} / \mathrm{IO}_{3}{ }^{-}\right)$, ethylenediaminetetraacetic acid (EDTA), and potassium ferrocyanide $\left(\mathrm{K}_{4} \mathrm{Fe}(\mathrm{CN})_{6}\right)$ were obtained from Fisher Scientific.

Photolysis samples were prepared by slurrying the pigment and 2.0 weight percent of platinum or iridium black as co-catalyst in methylene chloride and then feathering it into the surface of an acrylic flat. Pt was used as co-catalyst in the $\mathrm{H}_{2}$ evolution runs, while Ir was employed for $\mathrm{O}_{2}$ evolution. Samples were mounted vertically in a photocell containing $1.0 \mathrm{M} \mathrm{NaOH}$ solution and a $0.2 \mathrm{M}$ concentration of an electron transfer agent. Illumination source was a $1000 \mathrm{~W}$, ozone free, Xe arc lamp, passed through a 4-inch water filter. A $400 \mathrm{~nm}$ cut-off filter was sometimes used to determine the relative contribution of visible versus ultraviolet light to the gas evolution reaction. Gas volumes were sampled via an SRI 8610A gas chromatograph, equipped with a Hayesep DB column and thermal conductivity detector. The UV-visible reflectance spectra were obtained on a Shimadzu UV-2401 spectrophotometer and transformed using the KubelkaMunk equation.

Cyclic voltammetric experiments were run using an EG\&G Princeton Applied Research Potentiostat/Galvanostat model 273A with data being recorded using a Hewlett Packard 7015B chart recorder. A three electrode, single compartment configuration was used, with a platinum mesh counter electrode, and a saturated calomel reference electrode.

For the systems work, an electrochemical equivalent of a dual bed cell was constructed. The idea was to have microelectrode arrays in close proximity to each other that would perform their respective electrode reactions, namely, $\mathrm{H}_{2}$ evolution and mediator oxidation. This was done by stringing $\mathrm{Ni}$ wire back and forth across a piece of perforated electrical circuit board in such a way that alternate parallel wires belonged to an electrically isolated system. The result was an "interdigitated" array of Ni metal wire that would function as an electrochemical equivalent of a dual bed cell. The entire container was agitated on a New Brunswick Scientific Innova 2000 platform shaker at $100 \mathrm{rpm}$ to ensure good mixing and simulate flowing conditions.

\section{Results and Discussion}

\section{Photolytic gas evolution studies}

In Table 1, results for the various photolysis runs are shown. A photocatalyst would be paired with a given redox agent of varying Ox/Red ratio. The use of a UV cut-off filter is indicated. The resulting gas evolution, be it $\mathrm{H}_{2}$ or $\mathrm{O}_{2}$ evolution, is listed in microliters. Trials attempting to measure $\mathrm{O}_{2}$ evolution without using the cut-off filter did succeed in evolving large amounts of $\mathrm{O}_{2}$, but were ultimately rejected when it was determined that much of the $\mathrm{O}_{2}$ was resulting from the UV photodecomposition of iodate ion. This 
phenomenon was not observed when the Red form of the redox couple was employed, so that $\mathrm{H}_{2}$ evolution data acquired without the UV filter could be taken.

Several trends can be noted from the table below. The perylene diimide was shown to evolve $\mathrm{O}_{2}$ when $\mathrm{IO}_{3}{ }^{-}$ion was used as electron acceptor. On the other hand, the pigment evolved $\mathrm{H}_{2}$ when $\mathrm{I}^{-}$was used as electron donor. This was something of a surprise, since previous comparisons of redox potentials, gas phase ionization potentials, and molecular orbital calculations showed that the excited state donor level of perylene diimide is insufficiently negative to reduce water [8]. It should be noted, however, that UV light was required to drive the $\mathrm{H}_{2}$ evolution reaction. Indanthrone behaved in a similar manner; it can promote $\mathrm{O}_{2}$ evolution using visible light, but with a strong UV component, $\mathrm{H}_{2}$ could also be formed.

Table 1. Gas Evolution Data for Immobilized Dispersions of Organic Pigments

\begin{tabular}{|c|c|c|c|c|c|}
\hline Photocatalyst & Redox agent & $\begin{array}{c}\text { Initial Ox:Red } \\
\text { ratio }\end{array}$ & $\begin{array}{l}U V \text { cut-off } \\
\text { filter }\end{array}$ & $H 2, \mu L$ & $\overline{O 2, \mu L}$ \\
\hline Perylene diimide & $\mathrm{IO}_{3}{ }^{-}$ & 1:0 & $\mathbf{Y}$ & - & 32 \\
\hline Perylene diimide & $\mathbf{I}^{-}$ & $0: 1$ & $\mathbf{N}$ & 17 & - \\
\hline Indanthrone & $\mathrm{IO}_{3}^{-}$ & 1:0 & $\mathbf{Y}$ & - & 45 \\
\hline Indanthrone & $\mathbf{I}^{-}$ & $0: 1$ & $\mathbf{N}$ & 146 & - \\
\hline CuPc & $\mathbf{I}^{-}$ & $0: 1$ & $\mathbf{N}$ & 113 & - \\
\hline CuPc & $\mathbf{I}^{-}$ & 1:1 & $\mathbf{N}$ & 90 & - \\
\hline CuPc & $\mathbf{I}^{-}$ & 1:1 & $\mathbf{Y}$ & 10 & - \\
\hline CuPc & EDTA & $0: 1$ & $\mathbf{Y}$ & 5.3 & - \\
\hline CuPc & EDTA + I' & $0: 1$ & $\mathbf{Y}$ & 5.0 & - \\
\hline CuPc & $\mathrm{K}_{4} \mathrm{Fe}(\mathrm{CN})_{6}$ & 0:1 & $\mathbf{Y}$ & 3.9 & - \\
\hline NiPc & $\mathbf{I}^{-}$ & $0: 1$ & $\mathbf{N}$ & 23 & - \\
\hline VOPc & $\mathbf{I}^{-}$ & 0:1 & $\mathbf{N}$ & 26 & - \\
\hline quinacridone & $\mathbf{I}^{-}$ & $0: 1$ & $\mathbf{N}$ & 116 & - \\
\hline quinacridone & $\mathbf{I}^{-}$ & 1:1 & $\mathbf{Y}$ & 8 & - \\
\hline
\end{tabular}

1.0 M NaOH electrolyte, $0.2 \mathrm{M}$ mediator concentration 6.0 h Xe lamp exposure

Data for photocatalysts that were expected to be selective for $\mathrm{H}_{2}$ evolution are also shown. Once again there was a strong UV light effect, but nevertheless, a measurable amount of $\mathrm{H}_{2}$ derived from visible light could be obtained in some cases. Using visible light only, choice of redox mediator had little effect on the rate of $\mathrm{H}_{2}$ evolution from PtCuPc. If anything, the more reversible ferrocyanide couple gave a lower rate of $\mathrm{H}_{2}$ evolution. This trend will be borne out in the electrochemical tests to be discussed below.

In terms of complementary absorption spectra, our most favored combination of pigments was to pair copper phthalocyanine with the perylene diimide. Their visible spectra are shown in Figure 2 below. While the perylene diimide absorbs mainly in the blue region, giving it a reddish hue, the phthalocyanine absorbs in the yellow to red part of the visible 
spectrum, and so has a strong blue color. Using the pigments in a tandem arrangement enables absorption of a majority of the visible spectrum.

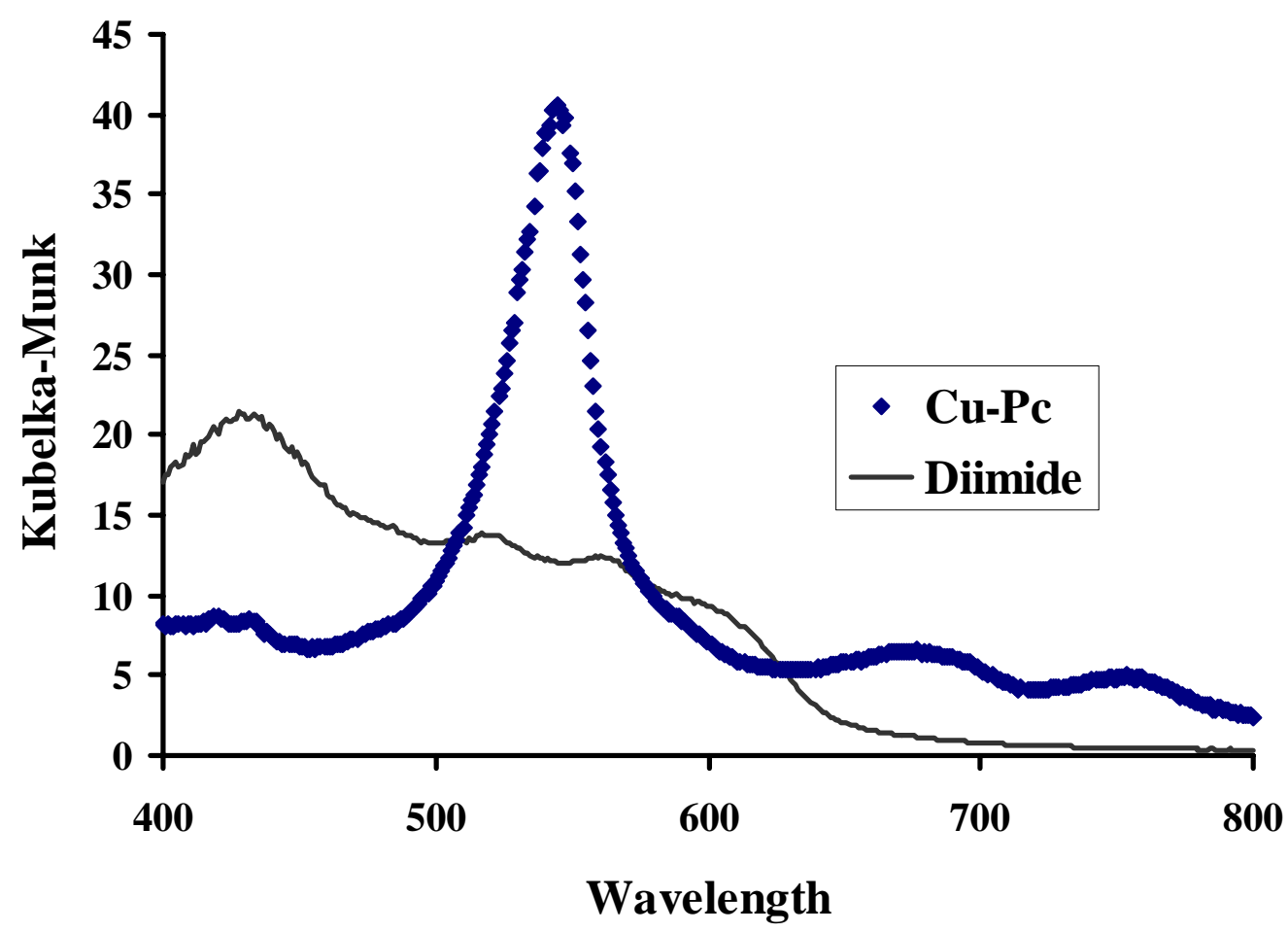

Figure 2. Absorption Spectra of Solid Films of CuPc and Perylene Diimide.

Observation of $\mathrm{H}_{2}$ and $\mathrm{O}_{2}$ evolution from respective photocatalysts with the same redox electrolyte $\left(1: 1 \mathrm{I}^{-} / \mathrm{IO}_{3}{ }^{-}\right)$using visible light can be regarded as a success, but efficiencies are quite low. Our preliminary determination, based on materials costs, is that the dual bed could produce $\mathrm{H}_{2}$ at $\$ 13 / \mathrm{mBtu}$ if the solar-to- $\mathrm{H}_{2}$ energy conversion efficiency of the system is $8 \%$. [9] Therefore, the gas evolution rates are perhaps 1000-fold less than is necessary for practical application.

\section{Systems studies: reversibility of redox mediator}

In the above section, results were shown for $\mathrm{H}_{2}$ evolution from alkaline iodide solution, and $\mathrm{O}_{2}$ evolution from alkaline iodate solution. For both modules to function as an integrated system, the redox solution exiting one module must be active in the other. This requires that redox mediator form Red be substantially converted to Ox while in the $\mathrm{H}_{2}$-evolving module, and vice versa for the $\mathrm{O}_{2}$ module. The reversibility, or relative rate constants for forward and reverse reactions, will obviously have a bearing on this feature. Therefore, the effect of reversible versus irreversible redox couples as redox mediators in dual bed systems was examined. Several redox couples representing a spectrum of reversibilities were chosen. As an example of a reversible redox couple, potassium ferrocyanide was employed. The iodide/iodate couple was taken as an example of a quasi-reversible system. Finally, benzhydroquinone, $\mathrm{H}_{2} \mathrm{Q}$, was chosen as an irreversible system. 
While one normally considers $\mathrm{H}_{2} \mathrm{Q}$ to be a reversible couple, in fact in strong alkali the electro-generated quinone form cannot find protons to enable reduction on the return
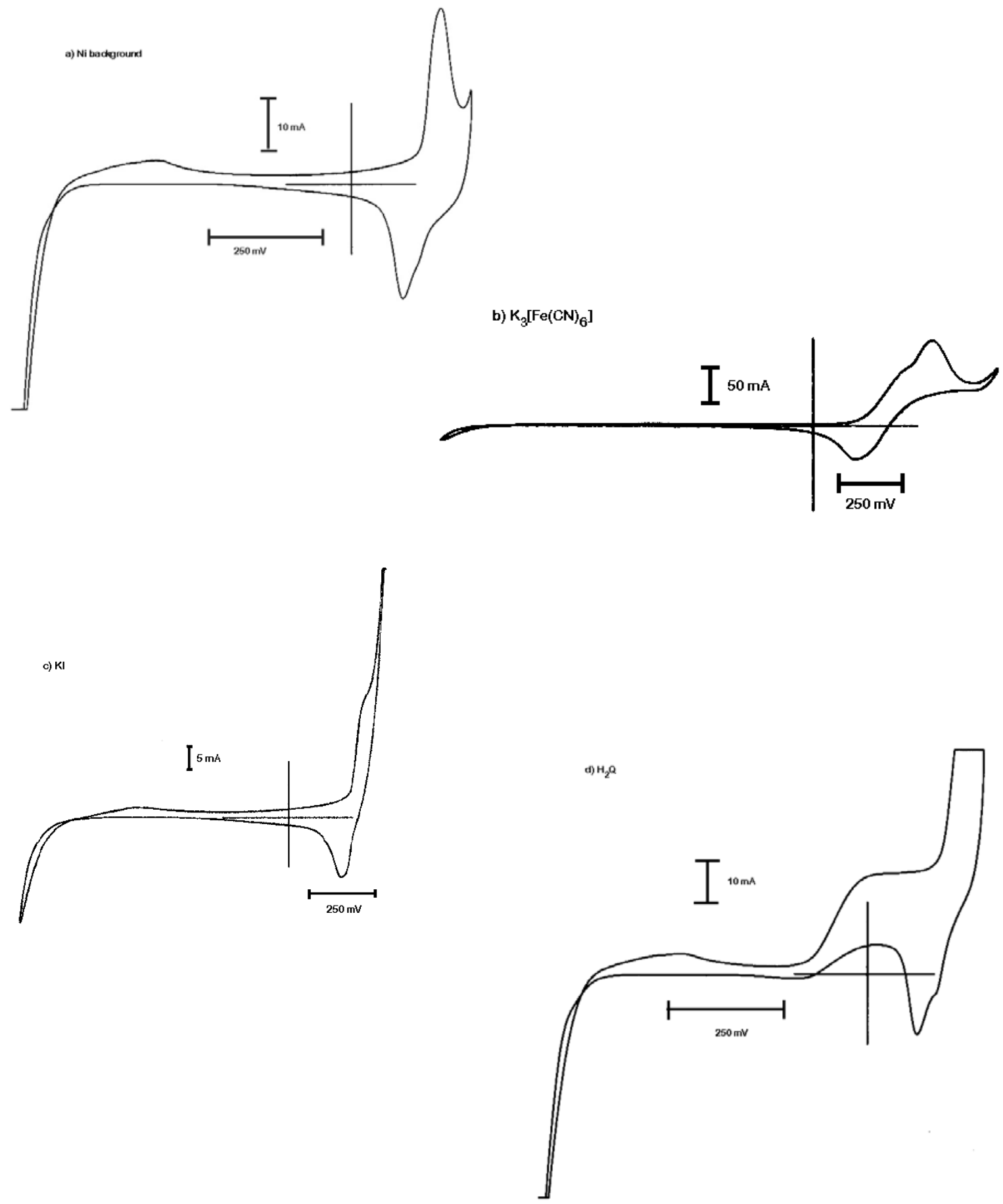

Figure 3. Cyclic Voltammograms of Reversible, Quasi-Reversible, and Irreversible Redox Couples on Ni Wire. a) Ni background; b) $\mathrm{K}_{4}\left[\mathrm{Fe}(\mathrm{CN})_{6}\right]$; c) KI; d) benzoquinone. 1.0 M NaOH; 0.1 M redox couple as marked; $50 \mathrm{mV} / \mathrm{s}$, Ar purged solution, SCE reference. 
voltage sweep, and so is completely irreversible. The cyclic voltammograms for the several redox species on $\mathrm{Ni}$ wire electrode, as well as an alkaline background cycle, are shown in Figure 3. The intent is that Ni may be a cheap co-catalyst substitute for Pt in the $\mathrm{H}_{2}$-evolving module and $\mathrm{NiO}_{\mathrm{x}}$ for $\mathrm{Ir}$ in the $\mathrm{O}_{2}$-evolving module.

The Ni wire itself shows background activity in alkaline electrolyte, exhibiting waves for oxide formation and reduction in the positive potential region, and moderately rapid $\mathrm{H}_{2}$ evolution and reoxidation in the negative region. The ferrocyanide does not appear to exhibit classic reversibility in terms of peak to peak separation, but the size of the electrolysis waves on forward and reverse sweeps are equal in size, and so it is functionally reversible. Also note that the current scale is five times larger than the other voltammograms. The $\mathrm{I}^{-} / \mathrm{IO}_{3}{ }^{-}$couple showed rather poor kinetics; its presence was more noticeable in terms of its ability to inhibit $\mathrm{Ni}$ oxidation and $\mathrm{H}_{2}$ evolution than any voltammetric waves of its own. The iodine species are apparently adsorbed to the electrode surface throughout the electrochemical cycle. The $\mathrm{H}_{2} \mathrm{Q}$ voltammogram was characterized by a single anodic wave near the zero of potential, superimposed on the $\mathrm{Ni}$ background.

Having identified reversible, partly reversible, and irreversible redox couples on our Ni wire arrays, a series of dual bed simulations was attempted involving an exhaustive electrolysis of the redox mediator. Cell current versus time was measured, as well as the extent of $\mathrm{H}_{2}$ evolution. This enabled us to subsequently determine the coulombic efficiency of the cell. The results are shown in Table 2 below. At $1.5 \mathrm{~V}$, the reversible potassium ferrocyanide couple enabled $\mathrm{H}_{2}$ evolution at only a $16 \%$ efficiency after $24 \mathrm{~h}$, i.e., only $16 \%$ of the cathode current was due to hydrogen production, the balance ostensibly being ferricyanide reduction. Thus, even though the steady state current for the reversible couple was much higher than the others, the actual rate of $\mathrm{H}_{2}$ production corresponded to $13.3 \mathrm{~mA}$, in the same range as the other redox couples.

Table 2. Coulombic Efficiency $(\eta)$ of $\mathbf{H}_{2}$ Evolution from a Ni Wire Array Using Redox Agents Possessing Varying Degrees of Reversibility.

\begin{tabular}{c|ccccc}
\hline Redox agent & Type & $V_{\text {appl }}(\mathrm{V})$ & $I_{\text {sS }}(\mathrm{mA})$ & $\eta$ after $1 \mathrm{~h}$ & $\eta$ after $24 \mathrm{~h}$ \\
\hline $\mathrm{K}_{4}\left[\mathrm{Fe}(\mathrm{CN})_{6}\right]$ & reversible & 1.5 & 83 & $65 \%$ & $16 \%$ \\
$\mathrm{KI}$ & quasi-reversible & 1.7 & 13 & $65 \%$ & $8 \%$ \\
$\mathrm{H}_{2} \mathrm{Q}$ & irreversible & 1.2 & $6-8$ & $61 \%$ & $97 \%$ \\
$\mathrm{H}_{2} \mathrm{Q}$ & irreversible & 1.5 & 19 & $88 \%$ & $87 \%$ \\
\hline
\end{tabular}

\section{$0.1 \mathrm{M}$ concentration of redox agent in $1.0 \mathrm{M} \mathrm{NaOH}$.}

$\mathrm{V}_{\text {appl }}=$ applied voltage; $\mathrm{I}_{\mathrm{ss}}=$ steady state current

The iodide system also showed a steady drop in $\mathrm{H}_{2}$ evolution rate from the outset, ultimately reaching $8 \%$, for an effective $\mathrm{H}_{2}$ steady state current of $\sim 1 \mathrm{~mA}$, much lower than either of the other two redox couples. This result can be explained from a dual effect of a build-up in iodate concentration: 1) more iodate ion is available for reduction 
at the negative electrode; and 2) iodate adsorption on the Ni cathode inhibits competitive $\mathrm{H}_{2}$ evolution.

On the other hand, benzoquinone electrolysis maintained up to $97 \%$ efficiency for $\mathrm{H}_{2}$ evolution over the same period. The difference in efficiency between 1.2 and $1.5 \mathrm{~V}$ was attributed to the onset of $\mathrm{O}_{2}$ evolution at the higher voltage. The steady state current for $\mathrm{H}_{2}$ evolution at $1.5 \mathrm{~V}$ was $16.5 \mathrm{~mA}$, the highest of the group.

\section{Conclusion}

Organic pigments were immobilized along with noble metal co-catalysts on acrylic flats and tested for gas evolution. Selective gas evolution using visible wavelength light was observed for a number of materials

Pigments whose electronic structures were considered favorable for either oxidative or reduction water-splitting were immobilized on acrylic substrates along with a noble metal co-catalyst and tested under a Xe lamp in the presence of an appropriate redox species in alkaline solution. While the photoresponse was dominated by UV absorption, it was nevertheless shown that certain pigments could absorb visible wavelength light and selectively evolve $\mathrm{H}_{2}$ or $\mathrm{O}_{2}$. Copper phthalocyanine and quinacridone were shown to evolve $\mathrm{H}_{2}$, and perylene diimide and indanthrone evolved $\mathrm{O}_{2}$.

If the initial mediator concentration was either all Ox or all Red, mediator-driven gas

evolution was easily observed. If, however, the cells were operated under nearly equal concentrations of Ox and Red, the effect was quite difficult to achieve. This means that the product of the mediator conversion reaction builds up, until the back reaction rate nulls out the forward one. 
The lack of reversibility proved to be the deciding factor in the long term production of $\mathrm{H}_{2}$. The reversible couple produced a comparable amount of $\mathrm{H}_{2}$, but did so very inefficiently. In the real situation outdoors under insolation, the incident light intensity may become rate limiting. In that case, the irreversible couple would make much better use of the incoming sunlight.

On the other hand, in the $\mathrm{H}_{2} \mathrm{Q}$ case there will have to be some sort of electrolyte conversion or exchange between dual bed modules so as to make quinone reduction possible and then to inhibit reoxidation. The development of a more sophisticated redox mediator may be necessary.

\section{References}

1. K. Rajeshwar, P. Singh, and J. DuBow: Energy Conversion in Photoelectrochemical Systems - A Review, Electrochimica Acta, 23 (1978) 1117-1144.

2. M. Aizawa, M. Hirano, and S. Suzuki: Photoelectrochemical Energy Conversion System Modeled on the Photosynthetic Process, Electrochimica Acta, 24 (1978) 1185-1190.

3. H. Tributsch and L. Pohlmann: Synergetic Molecular Approaches Towards Artificial and Photosynthetic Water Photoelectrolysis, J. Electroanal. Chem., 396 (1995) 53-61.

4. A.J. Bard: Design of Semiconductor Photoelectrochemivcal Systems for Solar Energy Conversion, J. Phys. Chem., (1982) 86, 172-77.

5. J.D. Meakin, R.W. Birkmire, L.C. DiNetta, P.G. Lasswell, and J.E. Phillips: Thin Film Tandem Solar Cells Based on CuInSe, Solar Cells, 16 (1986) 447-455.

6. $\quad$ K. Zwibel: Photovoltaic Cells, Chem. and Eng. News, July 7, 1986, 34-48.

7. D.K. Slattery, C.A. Linkous, and N.E. Gruhn: Organic Pigments as Photocatalytic Agents in a Solar Water-Splitting Scheme. Hydrogen Energy Progress XIII. Proceedings of the $13^{\text {th }}$ World Hydrogen Energy Conference, vol 1, June 12-15, 2000, Beijing, China,. 390-395.

8. D.K. Slattery, C.A. Linkous, N.E. Gruhn, and J.C. Baum: Semiempirical MO and Voltammetric Estimation of Ionization Potentials of Organic Pigments. Comparison to Gas Phase Ultraviolet Photoelectron Spectroscopy, Dyes and Pigments, 49 (2001) 21-27. 
9. D.L. Block: Comparative Costs of Hydrogen Produced from Photovoltaic Electrolysis and from Photoelectrochemical Processes. Hydrogen Energy Progress XII. Proceedings of the $12^{\text {th }}$ World Hydrogen Energy Conference, vol 1, June 21-26, 1998, Buenos Aires, Argentina, 185-194.

Dr. Clovis A. Linkous, tel. 321-638-1447, e-mail: calink@fsec.ucf.edu. Dr. Linkous received his doctoral degree from Michigan State University in 1983. His thesis research involved photoelectrochemistry of organic semiconductors. He then worked at Brookhaven National Laboratory until 1989, achieving scientist rank. Electro-reduction of oxygen using non-noble metal catalysts and high temperature steam electrolysis were among the topics investigated there. He then spent a year at Electron Transfer Technologies, an electrochemical engineering company near Princeton, New Jersey. In 1990 Dr. Linkous joined the staff at the Florida Solar Energy Center as a senior research scientist. There he has studied advanced membrane technology for water electrolysis and fuel cells, as well as photocatalytic chemistry of semiconductor particulates.

Dr. Darlene K. Slattery, tel. 321-638-1449, email: dkslatt@fsec.ucf.edu. Dr. Slattery, a senior research chemist, joined Florida Solar Energy Center in 1989 after completing her M.S. in industrial chemistry. She subsequently received her Ph.D. in chemistry, with a dissertation involving the photocatalytic decomposition of water. In addition to her expertise in photocatalysis, Dr. Slattery is a recognized expert in hydrogen storage using metal hydrides. Dr. Slattery is the author or co-author of more than two dozen publications spanning topics from synthetic organic chemistry and the fluorination of organics, to the calculation of theoretical ionization potentials, water splitting using both organic and inorganic semiconductors and storing hydrogen in metal hydrides.

[i] Zhang X, Shetty AS, Jenekhe SA. Macromolecules 1999; 32: 7422-7429.

[ii] Liu S-F, Wu Q, Schmider HL, Aziz H, Hu N-X, Popovic Z, Wang S. J Am Chem Soc 2000; 122: 3671-3678.

[iii] For example, compilation of experimental IPs of organic molecules can be found in: Kimura K, Katsumata S, Achiba Y, Yamazaki T, Iwata S. Handbook of HeI Photoelectron Spectra of Fundamental Organic Molecules. Tokyo: Japan Scientific Societies Press, 1981; Heilbronner E, Maier JP. In Brundle CR, Baker AD, Editors. Electron Spectroscopy: Theory, Techniques and Applications, Vol. I. New York: Academic Press, 1977. p. 205-293; Turner DW, Baker C, Baker 
AD, Brundle CR. Molecular Photoelectron Spectroscopy. New York: WileyInterscience, 1970.

[iv] Slattery DK, Linkous CA, Gruhn NE. Polymer Preprints 2000; 41: 866-867.

[v] Salem L. Molecular Orbital Theory of Conjugated Systems. Reading, Massachusetts: W.A. Benjamin, 1974 p 155.

[6] Westcott BL, Gruhn NE, Enemark JH. J Am Chem Soc 1998; 120: 3382-3386.

[7] Hsieh BR, Melnyk AR. Chem Mater 1998; 10: 2313-2316.

[8] MacColl A. Nature 1949; 163: 138-139.

[9] Dewar MJS, Hashmall JA, Trinajstic NJ. Am Chem Soc 1970; 92: 5555-5559.

[x] Slattery DK. Ph.D. Dissertation, Florida Institute of Technology, 1999.

[xi] Cornil J, Vanderdonckt S, Lazzaroni R, dos Santos DA, Thys G, Geise HJ, Yu LM, Szablewski M, Bloor D, Logdlund M, Salaneck WR, Gruhn NE, Lichtenberger DL, Lee PA, Armstrong NR, Bredas JL. Chem Mater 1999; 11: 2436-2443.

[xii] Cornil J, Gruhn NE, dos Santos DA, Malagoli M, Lee PA, Barlow S, Thayumanavan S, Marder SR, Armstrong NR, Brédas JL. J Phys Chem A, submitted (update possible?).

[13] Stern DA, Wellner E, Salaita GN, Laguren-Davidson L, Lu F, Hubbard AT. J Am Chem Soc 1988; 110: 4885-4893.

[14] Janietz S, Bradley DDC, Grell M, Giebeler C, Inbasekaran M, Woo EP. Applied Phys Lett 1998; 73: 2453-2455.

[15] Anderson JL, Coury Jr LA, Leddy J. Anal Chem 1998; 70: 519R-589R.

[16] Yang C, He G, Wang R, Li Y. J Electroanal Chem 1999; 471: 32-36. 
[17] Bauer D, Foucault A. J Electroanal Chem and Interfacial Electrochem 1972; 39:385-394.

[18] Paul RC, Kaushal R, Pahil SS. J Indian Chem Soc 1967; 44: 920-926.

[19] Bard AJ, Faulkner LR. Electrochemical Methods, Fundamentals and Applications. New York: Wiley \& Sons, Inc, 1980. p. 519-534.

[20] Phelps J, Santhanam KSV, Bard AJ. J Am Chem Soc 1967; 89: 1752-1753.

[21] Miller LL, Nordblom GD, Mayeda EA. J Org Chem 1972; 6: 916-918.

[22] Loutfy RO, Sharp JH. Photographic Science and Engineering 1976; 20(4): $165-174$.

[23] Tang TB, Yamamoto H, Imaeda K, Inokuchi H, Seki K, Okazaki M, Tani T. J Phys Chem 1989; 93: 3970-3973. 